\title{
Impact of river flow modification on wetland hydrological and morphological characters
}

\author{
Tamal Kanti Saha \\ University of Gour Banga \\ Swades Pal \\ University of Gour Banga \\ RAJESH SARDA ( $\sim$ rajeshsarda127@gmail.com ) \\ University of Gour Banga
}

\section{Research Article}

Keywords: Flow alteration, Wetland hydrology, Wetland fragmentation, Active flood plain, Hydrological strength modeling, Machine learning models, and Wetland security state

Posted Date: February 24th, 2022

DOI: https://doi.org/10.21203/rs.3.rs-1251492/v1

License: (c) (1) This work is licensed under a Creative Commons Attribution 4.0 International License. Read Full License 


\section{Impact of river flow modification on wetland hydrological and morphological characters}

2 Dr. Tamal kanti Saha ${ }^{2}$, Dr. Swades $\mathrm{Pal}^{1}$, and Rajesh Sarda ${ }^{3 *}$

3

$4{ }^{1}$ Professor, Department of Geography, University of Gour Banga, Malda-732103, West Bengal, India,

$5 \quad$ Email: swadespal2017@gmail.com

$6{ }^{2}$ Researcher, Department of Geography, University of Gour Banga, Malda-732103, West Bengal, India,

$7 \quad$ Email: tamalkantisaha999@gmail.com

$8{ }^{3}$ Research Scholar, Department of Geography, University of Gour Banga, Malda-732103, West Bengal,

9 India, Email: rajeshsarda127@gmail.com

$10 *$ Corresponding author 


\section{Abstract}

A good number of researchers investigated the impact of flow modification on hydrological, ecological, geomorphological conditions in a river. A few works also focused on hydrological modification on wetland with some parameters but as far the knowledge is concerned, linking river flow modification to wetland hydrological and morphological transformation following an integrated modeling approach is almost absent. The current study aimed to explore the degree of hydrological alteration in the river and its effect on downstream riparian wetlands adopting advanced modeling approaches. After damming maximally 67 to $95 \%$ hydrological alteration was recorded in respect to maximum, minimum, and average discharges. Wavelet transformation analysis figured out a strong power spectrum after 2012 (damming year). Due to attenuation of flow, the active inundation area was reduced by $66.29 \%$. After damming, $524.03 \mathrm{~km}^{2}(48.97 \%$ to total pre-dam wetland) was completely obliterated. Hydrological strength (HS) modeling also reported areas under high HS was declined by $14 \%$ after post-dam condition. WSS and HS matrix, a new approach, used to feature wetland coupling inundation connectivity and current hydrological state. HS under critical and stress wetland hydrological security zones deteriorated strength modeling, Machine learning models, and Wetland security state. in the post-dam period. The morphological transformation was also well recognized showing an increase of area under the patch, edge, and decrease of the area under large core area. All these findings established a good linkage between river flow modification and wetland transformation and it provided a good clue for managing wetland.

\section{Keywords}

Flow alteration, Wetland hydrology, Wetland fragmentation, Active flood plain, Hydrological

\section{Introduction}

People have been continuously changing river systems to meet their water demands through various activities, and one of these activities is the construction of dams across river, which dramatically modify the natural river flow regime in its downstream (Wang et al., 2019; Zheng et al., 2019; Arévalo-Mejía et al., 2020). This direct regulation-related effect will undoubtedly continue to have an impact on rivers in the future decades, with potentially significant and unexpected consequences for their morphodynamics and ecosystems, as well as the concerned flood plain areas (van Oorschot et al., 2018; Zheng et al., 2019; Pal and Sarda, 2020). River flow alterations seem like the most significant modification of the fluvial landscape on the earth's 
surface (Wang et al., 2020; Chen et al., 2021; Pal and Sarda, 2021a). A good number of researchers believe that flow modification is one of the emerging challenges since it changes the downstream flow regime in terms of total flow, size, timing, length, rate of change, and water quality (Pal et al., 2019; Huang et al., 2019; Amenuvor et al., 2020; Du et al., 2020; Pal and Sarda, 2020; Pal et al., 2020). As a result, it can reduce the connection of the main channel with the flood plain and it not only arrests the water supply to the flood plain but also limits the natural dispersion of fish and macroinvertebrate species towards the flood plain for sustaining the flood plain biodiversity (Rolls et al., 2012). Li et al. (2017) documented since 1991 to 2009, the average flow of Southeast Asia's Mekong river was decreased by 82 percent. Pal (2016b) showed that the Rubber dam on the Atreyee river in Bangladesh has attenuated 84 percent maximum flow and 56 percent average flow. As per Xue et al. (2017), damming on Tarim river basin of China, downstream flow was reduced by $68.7 \%$, which made the hydrological shortage and ecological stress. According to Pal and Talukdar (2020) in the case of the Punarbhaba river in India-Bangladesh, the average flow was decreased by $36 \%$ due to dam installation. Ali et al. (2019) reported 17-27\% attenuation of the flow of the Yangtze River after damming and warned for water shortages without implementation of suitable management techniques. Wang et al. (2018), Pal et al. (2019) observed the significant hydrological modification in Yangtze, Tangon rivers throughout the world.

The construction of the dam not only changed the hydrological system of a river (Pal, 2016a) but also modified the hydro-ecological regime and morphological character of the riparian wetlands by reducing flood frequency, magnitude, squeezing active flood plain area, fragmenting the wetland landscape, and so on. (Gain and Giupponi, 2015; Pal and Saha, 2018; Zheng et al., 2019; Saha and Pal, 2019b; Wang et al., 2019; Duc et al., 2020; Smith et al., 2020; Pal and Sarda, 2020; Pal and Sarda, 2021b). Wetlands are the world's most unique, transitional, and productive ecosystems, holding around 6-8 percent of the earth's terrestrial area and indicating approximately 45 percent of the overall economic value among all global ecosystems (Finlayson, 2013; Mitsch and Gosselink, 2015). Changes in land use/cover, increase of population and their demands, changing lifestyles and requirements are all putting pressure on these wetlands. In comparison to other economic activities, these lands have always been treated as less valuable (Duc et al., 2020; Pal and Sarda, 2020; Smith et al., 2020). 
Several studies have discovered that damming has an unfriendly influence on the riparian zone, although, the fact that the dam is not the sole responsible factor for all such changes undoubtedly it is a dominant factor for altering riparian wetland hydrological and morphological character (Zheng et al., 2019; Pal et al., 2020; Talukdar and Pal, 2020). In recent times, the research community and the victims both have paid their attention to study this issue and trying to find some reasonable solution, because it is strongly related to ecological survival and livelihood sustainability (Pal and Saha, 2018; Wang et al., 2019; Zheng et al., 2019; Pal and Sarda, 2020). According to Zheng et al. (2019), hydrological changes were recognized in the lower portion of the Nenjiang River in Northeast China after dam building, and these changes contributed significantly to the 44 percent decline in riparian wetlands. Saha and Pal (2019a) reported that $45 \%$ of the active flood plain was lost after damming in the Atreyee river basin. According to Talukdar and Pal (2020), damming across the Punarbhaba river in India and Bangladesh reduced (2022) applied a water presence frequency approach for wetland consistency analysis. A limit. When a wetland is hydrologically affected adversely, its ecological function abilities, natural resource strength, and morphological characteristics also change accordingly (Bregoli et al., 2019; Aghsaei et al., 2020; Orimoloye et al., 2020). According to Kundu et al. (2021), flow change has an indicative impact on the state of wetland fragmentation as well as ecosystem services. Furthermore, shallowing water depth promotes agriculture extension inside wetland, which leads to wetland fragmentation (Pal and Saha, 2019a).

Integrated development of hydrological strength is very difficult since the hydrological data are not readily available (Jeziorska, 2019). Pal and Sarda (2020), Khatun et al. (2021), Pal et al. consistent wetland is good for hydrological strength. Water indices based on time series wetland maps were used for this. Water depth is also a prevalent hydrological component and such data is scarce. Khatun et al. (2021), Kundu et al. (2021), Pal and Sarda (2021a), Pal and Sarda (2021b) tried to develop it from satellite images. Onyango and Opiyo (2021), Pal and Sarda (2021b), Saha et al. (2021), Sahour et al. (2022) used Normalized difference water index (NDWI) for preparing water depth layers through a field-driven databased calibration process. Hydro-period means the period of water stagnation in the wetland in a year. Özelkan (2020), Kundu et al. (2021), Pal and Sarda (2021b), Teng et al. (2021) attempted to develop it through monthly water indices-based images. For compositing, the hydrological components and interpreting the overall 
121 change in the hydrological environment in wetland, modeling approaches like statistical, 122 knowledge-driven, and machine learning (ML) algorithms are recommended. Among these, ML modeling provides a good scope for solving non-linear relationships of the applied parameters in a very robust way. A good many ML methods like Random forest (RF) (Shaikhina et al., 2019; Han et al., 2020; Rahmati et al., 2020), Artificial neural networks (ANN) (Tian et al., 2019; Nhu et al., 2020), Reduced Error Pruning Tree (REPtree) (Chen et al., 2019; Ghasemain et al., 2020; Arabameri et al., 2021), Support vector machines (SVM) (Xiong et al., 2019; Singha et al., 2020; Bouramtane et al., 2021) and many more were applied by the scholars for predicting risk, the vulnerability of different kinds and reported credible result. Considering this, the present study also applied ML models for developing hydrological strength models using image-driven hydrological components. Since flood water is a reliable source of wetland, assessing flood extent over time and analyzing wetland within or beyond flood extent is also very useful (Greet et al., 2020; Karim et al., 2020). Flood simulation amongst is a reliable approach for this which is applied in this present case. Based on this, the wetland was classified into para and ortho-fluvial wetland by Ward and Stanford (1989). Para-fluvial wetlands are those that are directly linked with the river (Deforet et al, 2009; Mondal and Pal, 2018). Following their thinking, the wetland hydrological security state (WSS) was recognized in this present work.

From the literature survey, it is very clear that a good many studies dealt with river flow modification and its hydro-ecological, geomorphological consequences in downstream rivers (Yan et al., 2010; Li et al., 2017; Tonkin et al., 2018; Wang et al., 2018). A few works also devoted to exploring hydrological dynamics in the riparian wetland in consequence of hydrological modification in a river (Chakraborty et al., 2018; Zheng et al., 2019; Pal and Sarda, 2020; Pal and Sarda, 2021a; Pal and Sarda, 2021b; Pal et al., 2022). However, as far the knowledge is concerned there is a dearth of work linking river and riparian wetland hydrological modification selecting relevant hydrological parameters like pixel scale water depth, water presence consistency, hydro-period, river flood water connectivity, etc. But integrated spatial scale (pixel) analysis of hydrological conditions in the wetland concerning the degree of hydrological modification in a river triggered by damming is very vital for understanding the effect of it and devising sustainable planning for wetland management. Few case studies used field-driven data for doing this, but there is a lack of work covering a large geographical area. However, it is essential from the planning point of view. Therefore the current study aimed to 
152 examine the degree of hydrological modification in the river and riparian wetland concerning 153 damming and linking them. The work was also in a question that can hydrological modification 154 bring noticeable changes in wetland morphology promoting other factors of wetland 155 transformation?

\section{$156 \quad 2$. Study area}

157 Atreyee river (390 km long), an India Bangladesh transboundary river with assorted aquatic 158 ecosystems (Adel, 2013). In the lower portion of this basin, a lot of rain-fed and flood water-fed 159 wetlands are available and they are generally located close to the main river (Figure 1). The 160 majority of the wetlands are seasonal and highly inconsistent in water appearance. Water furnish 161 to the wetlands depends on occasional rainwater and the frequency, duration, magnitude of 162 inundation of the Atreyee river (Pal and Saha, 2018; Pal and Sarda, 2020; Pal et al., 2021, Pal 163 and Sarda, 2021a). Water harvesting from the mainstream for different economic and domestic 164 purposes has gradually been expanded. For upgrading irrigation supply, the Mohanpur rubber 165 dam was built over the Atreyee river in 2012 and this episode has enhanced the water shortage in 166 the downstream main river and its alongside wetlands. The time after the development of the 167 dam (2012 onward) is considered as a post-dam stage. After the damming impact, the river and 168 riparian scene have experienced a huge alteration in the hydrological regime (Pal and Sarda, 169 2020). River damming is brought about by $30.97 \%$ and $64.01 \%$ discharge curtailed during pre170 monsoon and post-monsoon seasons and it is additionally caused for dwindling water 171 accessibility in the wetland (Pal, 2016b; Pal and Saha, 2018; Pal and Sarda, 2020). This is also a 172 very evident reason for wetland hydrological alteration. Considering this the lower Atreyee river 173 basin has been considered as a special case. 

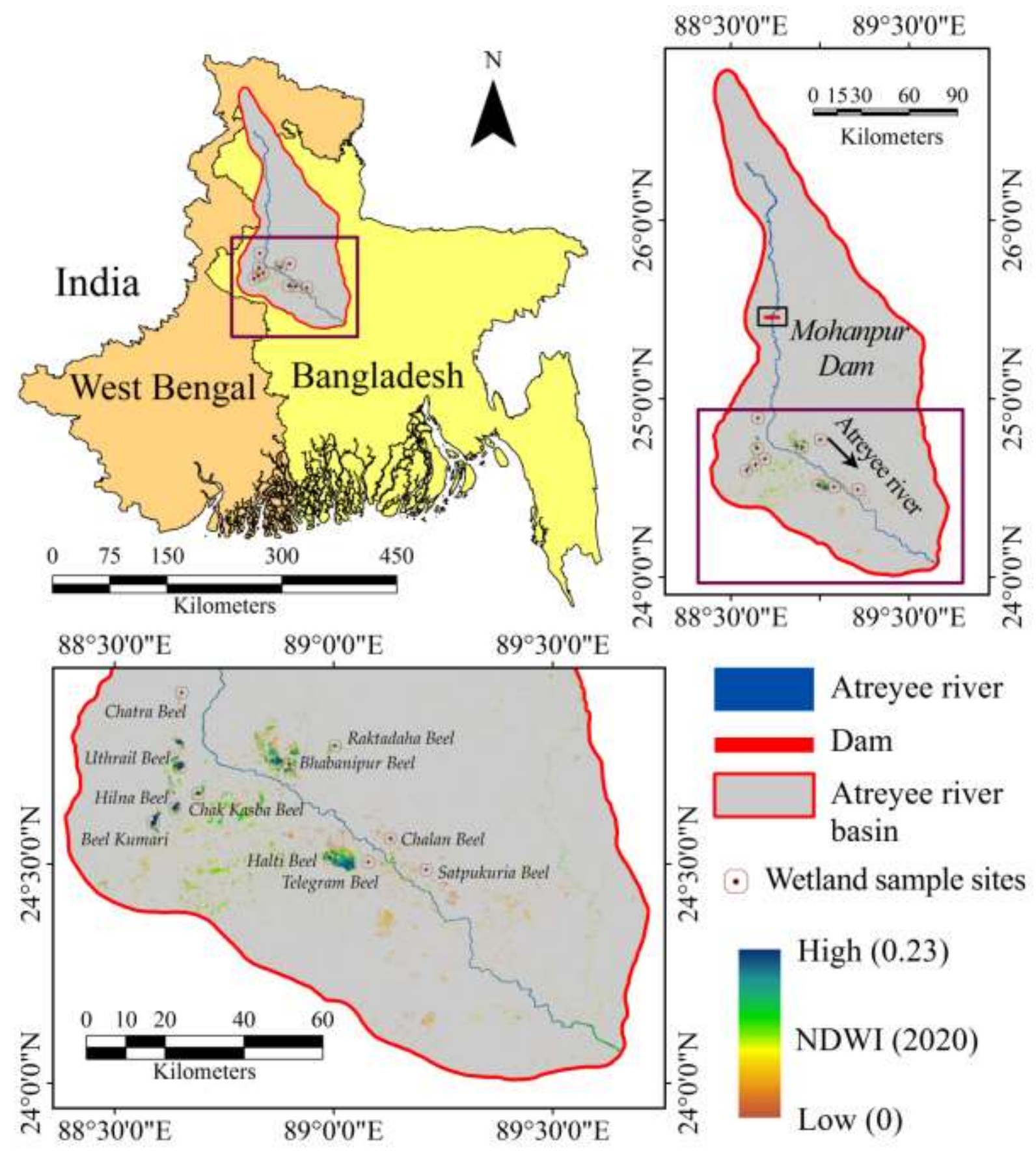

177 Figure 1: Location of the study area

\section{3. Materials}

179 To fulfill the objectives, consider three-hour interval discharge and water level data (from 1993

180 to 2018) that were obtained from the Joda bridge river gauge station in Balurghat for monitoring

181 hydrological modification, 2D flood modeling in the post-dam period. Specifically, for 2D

182 floodplain modeling, the SRTM DEM was employed. Landsat-TM satellite images characterize 
crucial and ongoing recordings of the earth's surface. We have separated the complete temporal spectrum dataset into two phases-pre and post-dam for pre and post-monsoon season to recognize the dam's influence. Over the last 33 years (1987-2020), cloud-free Landsat TM and OLI were used to detect and monitor the inundation state of wetlands. Detail descriptions of the images are provided in the supplementary section.

\section{Methods}

\subsection{Measuring flow alteration (heat mapping)}

There are many methods of measuring flow alteration like the Range of variability approach (Richter et al., 1998; Yang et al., 2008; Cheng et al., 2018; Ali et al., 2019; Tian et al., 2019), Revised range of variability approach (Ge et al., 2018), Histogram comparison approach (Huang et al., 2017), Histogram matching approach (Shiau and Wu, 2008; Huang et al., 2016). Among this range of variability approach adopted to measure the flow alteration of the Atreyee river. Besides, heat mapping is a good data visualization technique showing the changes of the magnitude of the phenomenon in a gradient of color in two dimensions (Barter and Yu, 2018). In this present context, a heat map was prepared using the time-series change of discharge data and change of discharge data in pre and post-dam years (1997 to 2018) about each month. Hydrological alteration of the post-dam period was computed about the average of the pre-dam period. The Data matrix for the pre-dam period doesn't show any alteration rather an anomaly of yearly discharge about the average of each respective month.

\subsection{Flow periodicity analysis}

For analyzing long-term time series variability, trend, periodicity Wavelet transformation technique is very useful (Talukdar and Pal, 2020). Wavelet transformation is a well-built mathematical signal processing technique that can offer both frequency and time domain information from both non-stationary and stationary data sets, which together is difficult to obtain from other standard methods (Santos et al., 2018). Fourier transformation can only provide time or frequency domain (Smith et al., 1998), however, the wavelet transformation method was built by modifying the Fourier transformation to receive both time and frequency domain information (Liu et al., 2016; Wang et al., 2018). Additionally, this method can construct a multi-resolution analysis. For an instance, at a low scale of wavelet transformation, it yields a good quality time resolution and at a high scale, it is just the opposite. This information is very 
214 imperative for any time series analysis like time series discharge change. In the case of non-

215 stationary time series data (mean, variance, covariance, and autocorrelation change over time but

216

217

221

222

223

225

226

227

228

229

230

231

232

233

234

235

236

237 (WD).

238

(WD). cannot return to its original position again), this method is well accepted and will be applied for hydro-meteorological data series.

Goupillaud et al. (1984) deemed first wavelets as a group of functions constructed from the translations and dilations of a single function, which is known as the "mother wavelet". The wavelet transform is defined by equation (1)

$\psi_{a, b}(t)=\frac{1}{\sqrt{|a|}} \psi\left(\frac{t-b}{a}\right) ; a, b \in R ; a \neq 0$

Where, the scale parameter is symbolized by ' $a$ ' that appraises the degree of compression, whereas, translation parameter that calculates the time location of the wavelet is presented by ' $b$ '. The ' $a$ ' parameter in the mother wavelet will be conditioned by the higher frequencies (smaller support in the time domain) when $|a|$ will be less than 1 . When $|a|_{\mathrm{a}}$ will is more than 1 , then $\psi_{a, b}(t)$ has a larger time width than $\psi(t)$ that will correspond to lower frequencies. Therefore, wavelets have time widths that are adapted to their frequencies that are the actual reason behind the achievement and exclusive usefulness of the Morlet wavelets in signal processing and time-frequency signal analysis.

\subsection{Method for measuring hydrological modification of wetland}

\subsubsection{Modification about hydrological components}

Measuring hydrological modification at a spatial level over a larger geographical area is a very difficult task due to the lack of spatial scale data availability. In this work, three major hydrological components were developed from multi-date image data at a pixel level. The components are (1) water presence frequency (WPF), (2) hydro-period (HP), and (3) water depth

For developing hydrological components of the wetland, month scale Normalized differences water index (NDWI) was first developed following Mcfeeters (1996) (Eq. 2). Saha and Pal (2018), Pal and Sarda (2020) endorsed that NDWI is a suitable water index for wetland delineation for this region. NDWI value $0-1$ signifies wetland. 


$$
N D W I=\frac{\text { Green }-N I R}{\text { Green }+N I R}
$$

243 WPF shows consistency of water appearance in a pixel over a considered time. The equation for computing WPF is Equation 3. WPF value ranges from 0-100\%. A value near 1 means irregular water appearance in a pixel and 100\% signifies that in all the considered years, water appeared in a pixel (Sarda and Das, 2018). For the convenience of analysis, the WPF spectrum was classified into three classes (a) high WPF (>67\%), (b) moderate WPF (33-67\%), and (c) low WPF (<33\%). For developing the WPF map from the satellite image, the first water index (Normalized difference water index (NDWI)) (Eq. 2) of each year was computed for the post-monsoon season. Each NDWI map was converted into a binary map assigning 0 to non-wetland and 1 to wetland pixel. All the binary maps of pre and post-dam periods were added separately and divided by the total number of considered years and expressed in percentage (Eq. 3).

$$
\operatorname{WPF}(\%)=\frac{\sum_{i=1}^{N} B F p i j}{N_{s}}
$$

Hydro-period map was developed from monthly NDWI maps. Binary NDWI maps of twelve months in a year were summed up following Pal and Sarda (2021a). The value may range from 0-12. 0 signifies no wet period in a year and 12 means perennial wetland. Both seasonal and perennial wetlands are ecologically important but perennial wetland has a better opportunity for species phenology over a long period and economic turnover (Milani et al., 2019). This approach is very efficient since it provides pixel scale hydro-period information over wider geographical areas. The finer temporal resolution may provide more authentic data for doing this than the Landsat product (temporal resolution: 16 days).

263 Water depth data is very crucial for analyzing the hydrological state of a wetland, but pixel scale 264 data, even point scale data is almost lagging. Khatun et al. (2021), Kundu et al. (2021), Pal and 265 Sarda (2021b) successfully attempted image-based derivation of water depth data at different points in time. Following them, the present work also applied this approach of water depth calibration of water indices (NDWI) using 130 field-driven sample depth data of nine wetland sites. The accuracy of this map largely depends on the number of field-driven data for calibration and suitable water indices. Abnormal natural and anthropogenic intervention on wetland water strongly withstand against establishing a relationship between spectral value and ground truth 
271 (Talukdar and Pal, 2020). Gao (1996) stated that NDWI value is related to water thickness. Good

272 water depth is related to the hydrological strength of the wetland since it provides sample 273 ecological niches of varying characteristics.

\section{$274 \quad 4.4$ Developing hydrological strength model}

275 Using WPF, HP, and WD, three machine learning (ML) algorithm-based hydrological strength

276

277

278

279

280

281

282

283

284

285

286

287

288

289

290

291

292

293

294

295

296

297

298

299

300 models were developed to see the change of hydrological strength in pre and post-dam periods. Artificial neural network (ANN), Random forest (RF), and Reduced error pruning tree (REPTree) hydrological strength models were built.

\subsubsection{Artificial neural network (ANN)}

ANN can work as a human mind and can powerfully anticipate the outcome from the countless factors model (Zhao et al., 2019; Nguyen et al., 2020; Saha et al., 2021). This is the justification for why, number of specialists have widely applied this model in several fields of examination (Choi et al., 2019, Zhao et al., 2019; Nguyen et al., 2020; Pal and Sarda, 2021). Here the researchers have widely used the multi-layer perceptron (MLP) algorithm. MLP is one of the most by and huge executed neural frameworks which are constantly set up with the backpropagation calculation (Choi et al., 2019, Zhao et al., 2019). The backpropagation algorithm was applied in MLP for the development of the network till the least error is reached inside the result and expected upsides of the ANN. In this calculation, the connection between the information is noticed and a transition rule is utilized to remove data from the fundamental layer (Paola \& Schowengerdt, 1995). The connections might be weighted in the given environment and are associated through unidirectional progressions of data produced from the input layer to concealed layer lastly to the output layer. This sort of multi-layer ANN model is skilled to get significance from the components WPF, depth consistency, and hydro-period duration of the wetland considered as a dependable information building WR models.

\subsubsection{Random forest (RF)}

Random forest (RF), presented by Breiman (2001) is a notable ensemble-learning calculation that is a blend of decision trees for gathering or backsliding to predict with a higher precision level. Besides, the RF method is broadly utilized for land use land cover classification, regression, and unsupervised learning (Behnia and Blais-Stevens, 2018; Camargo et al., 2019; Chen et al., 2020). RF comprises an ensemble of classifiers to establish a connection among 


\begin{tabular}{|c|c|}
\hline $\begin{array}{c}\text { Machine } \\
\text { learning } \\
\text { algorithms }\end{array}$ & Description of optimized parameters \\
\hline ANN & $\begin{array}{l}\text { Hidden layer- } 6 \text {, learning rate- } 0.3 \text {, momentum- } 0.2 \text {, seed-7, training time- } \\
500 \text {, validation threshold-20, Normal to binary filter-TRUE }\end{array}$ \\
\hline $\mathrm{RF}$ & $\begin{array}{l}\text { Batch size-100, seed-1, number of iteration-100, max depth-1, calc out of } \\
\text { bag-TRUE, Compute attribute importance-TRUE }\end{array}$ \\
\hline REPtree & $\begin{array}{l}\text { Batch size- } 100, \text { seed- } 3 \text {, max depth- }-1 \text {, minimum number- } 2.0, \text { minimum } \\
\text { variance proportion- } 0.001, \text { spread initial count-TRUE }\end{array}$ \\
\hline
\end{tabular}

factors and weight generation for each variable. The RF algorithm produces many trees during the training stage, and the last weight is created by averaging all the tree values. RF classification utilized the resampling procedure by randomly changing the predictive variables to build the variety in each tree (Arabameri et al., 2020). In this study, the datasets are of high dimensional nature so it is essential to join the effect of each component then the model can predict the water wealth of the wetland with a higher precision level.

\subsubsection{Reduced error pruning tree (REPtree)}

The Reduced error pruning tree is a fast machine learning algorithm, which consists of Reduced Error Pruning (REP) and the Decision Tree (DT) (Quinlan, 1987). The prime goal of this algorithm is to reduce the difficulty of the modeling procedure when utilizing enormous information (Mohamed et al., 2012). In this calculation, the DT is applied to rearrange the modeling strategy using a preparation dataset when the output of a decision tree is huge, and the REP was used to lessen the complicity of the structure of the tree (Mohamed et al., 2012). This strategy reduces the complexity of the decision tree model during the pruning process and limits the model error. The straightforward setup and pruning strategy gives better exactness and lessens the over-fitting issue (Pham et al. 2019). In pruning measure, a decision tree can be pruned into two different ways, for example, pre-pruning and post-pruning. Pre-pruning is quicker with less exactness whereas post-pruning gives better precision (Chen et al. 2019). In this examination, the post pruning strategy was used to generate a series of pruned trees and to recognize an exact sub-tree from the test dataset.

Table 1: Optimization statistics of the applied machine learning models 
324 Nampak et al. (2014) rightly stated that there is no merit in modeling with no scientific

325 significance; therefore, the validity and uncertainty of models need to be assessed. To 326 authenticate the performance of the wetland hydrological strength models, several statistical 327 measures including Sensitivity (SE), Specificity (SP), Kappa statistic (K), Area under the curve 328 (AUC) in receiver operating characteristic (ROC) curve, and Matthews's correlation coefficient 329 (MCC) were applied in this study. SE, SP, AUC, K values usually range from 0-1. A value near 3301 signifies a higher level of predictive agreement (Yang and Zhou 2015; Warrens and Pratiwi, 331 2016). MCC was used to check the quality of binary classification of machine learning models 332 (Chicco and Jurman, 2020). This coefficient ranges from -1 (complete disagreement in 333 prediction) to +1 (perfect agreement in prediction). The equations of the statistical measures are 334 put from Eq. 4-7.

$335 \quad S E=\frac{T P}{T P+F N}$

$336 \quad S P=\frac{T N}{T N+F P}$

$337 \quad$ Kappa statistic $=\frac{W_{o}+W_{e}}{1-W_{e}}$

$M C C=\frac{T P \times T N-F P \times F N}{\sqrt{(T P+F P)(T P+F N)(T N+F P)(T N+F N)}}$

339 Where, $\mathrm{TP}=$ True Positive; $\mathrm{TN}=$ True Negative; FP=False Positive; FN=False Negative; $\mathrm{W}_{\mathrm{o}}$ and $340 \quad \mathrm{~W}_{\mathrm{e}}=$ Observed and Expected agreement

$342 \quad 4.6$ Modification about lateral hydrological connectivity

$343 \quad$ 4.6.1 2D inundation modeling

344 The US Army Corps of Engineers developed HEC-RAS software to simulate floods using one345 dimensional (1D), two-dimensional (2D), and three-dimensional (3D) models. In the scenario of 346 a uniform cross-section channel, the 1D model can be utilized whereas, in the case of a channel 347 with different cross-sections, the 2D model is implemented. The 2D simulation model was 
employed for both the pre-dam and post-dam phases of the Atreyee river, taking into account variable cross-sections.

The median flood discharge is estimated for both the pre-dam and post-dam eras before flood models are simulated. The years 1993 and 2014 were chosen as the representative median flood years for both phases. Discharge data from flood periods (7 days) were placed in the dam's downstream sections, and flood simulation maps were created using the SRTM DEM. For the model's validation, a total of 188 flooded locations were chosen from around the basin. A GPS survey of flood areas was conducted to acquire ground reference sites. People's perspectives on the selected places were obtained to see if they were genuinely prone to flooding. Using field and model data, the Kappa coefficient was calculated. The estimated kappa coefficients for pre and post-dam periods respectively are 0.85 and 0.89 , denoting high agreement between model and field reality. (Eq. 8-10).

$\frac{\partial h}{\partial x}+\frac{\partial s}{\partial m}+\frac{\partial t}{\partial n}=0$

$\frac{\partial s}{\partial x}+\frac{\partial}{\partial m}\left(\frac{s^{2}}{w d}\right)+\frac{\partial}{\partial n}\left(\frac{s t}{w d}\right)=-\frac{n^{2} s g \sqrt{s^{2}+t^{2}}}{w d^{2}}-v w d \frac{\partial h}{\partial m}+s f+\frac{\partial}{\omega \partial m}\left(w d \tau_{m m}\right)+\frac{\partial}{\omega \partial n}\left(w d \tau_{m n}\right)$

$\frac{\partial t}{\partial x}+\frac{\partial}{\partial n}\left(\frac{t^{2}}{w d}\right)+\frac{\partial}{\partial m}\left(\frac{s t}{w d}\right)=-\frac{n^{2} t g \sqrt{s^{2}+t^{2}}}{w d^{2}}-v d \frac{\partial h}{\partial n}+y f+\frac{\partial}{\omega \partial n}\left(w d \tau_{n n}\right)+\frac{\partial}{\omega \partial m}\left(w d \tau_{m n}\right)$

Where, $w d$ is the depth of water $(\mathrm{m})$,

$s$ and $t$ are the definite flow in the $\mathrm{m}$ and $\mathrm{n}$ directions $\left(\mathrm{m}^{2} \mathrm{~s}^{-1}\right)$,

$h$ is the surface height $(\mathrm{m})$,

$v$ is the increase of rate due to gravity $\left(\mathrm{m} \mathrm{s}^{-2}\right)$,

$r$ is the Manning resistance,

$\omega$ is the water density $\left(\mathrm{kg} \mathrm{m}^{-3}\right)$,

$\tau_{m m e},{ }^{\tau_{n n}}$ and ${ }^{\tau_{m n}}$ are the components of the effective shear stress and $\mathrm{f}$ is the Coriolis $\left(\mathrm{s}^{-1}\right)$.

After producing inundation maps for both the pre-dam and post-dam phases, current-day wetlands were superimposed on these maps, and it was determined which section of a specific wetland is beyond or within the pre-dam and post-dam active flood plains. Wetlands are classified into three types based on their probability of receiving frequent floodwater. Wetlands that exceed the pre-dam flood limits are classified as having a critical status. Wetlands that are inside the pre-dam active flood limit but beyond the post-dam active flood limit are classified as 
stressed wetlands. Wetlands within the current flood limit are considered safe wetlands since they may receive frequent flood water.

\subsubsection{Classifying wetland security state (based on flood zones)}

Wetlands of the basin were classified based on lateral inundation zones before and after hydrological alteration due to damming. After overlapping inundation zones of pre and post-dam conditions, three zones were identified like (1) area inundated both during pre and post-dam periods (2) area beyond post-dam but within pre-dam inundation limits, and (3) area beyond both pre and post-dam flood limits. Wetlands were under three inundation zones were respectively treated as (1) safe, (2) stress, and (3) critical about hydrological security particularly in terms of lateral hydrological connectivity. Since in the rain-induced fluvial-flood plain region where floodwater is one of the dominant sources of wetland, classification on this basis is very crucial. Moreover, flood not only supplies water to the para-fluvial wetland but also supplies nutrients, fish seeds, different species seeds, remove pollutants, etc. So, analyzing flood water connectivity and classifying wetland is very essential. Here, it is to be remembered that a critical wetland doesn't mean the wetland is devoid of water, it may be supported by rainwater, seepage water but deprived of flood services.

\subsection{Morphological change of wetland (Fragmentation/shape sizes)}

Landscape morphology is itself a good indicator of wetland hydrological dynamics. The perennial and consistent wetland is less susceptible to morphological transformation than seasonal, ephemeral wetlands that are hydrological irregular, erratic, and provide a scope of activating invasive factors of wetland morphological change (Epting et al., 2018; Talukdar and Pal, 2019; Lee et al., 2020). Using Fragstat software wetland landscape of both pre and post-dam periods was classified into a patch, edge, perforated, small, medium, and large core, and the area under each category were accounted to show the morphological changes of the wetlands. Dynamics of patch frequency, area, edge area, a core area in between pre and post-dam periods help to explain the nature of influencing factors.

\subsection{Identifying associated modification}

There are different causes to be condemned for wetland loss, a hydro-ecological transformation like agricultural, built-up land extension, infrastructure development replacing wetland, attenuation of water availability, etc. However, the hydrological modification could be one fundamental transformation of wetland that can also invite some other related causes (Das and 
408 some case studies exploring the nature of hydrological transformation and associated other 409 causes directly from the field following the approach of the Millennium Ecosystem Assessment 410 (MEA, 2005) report. Different drivers, driver's impact, current trend, etc were surveyed for each 411 wetland.

\section{Results}

\section{$413 \quad 5.1$ Flow alteration (heat mapping)}
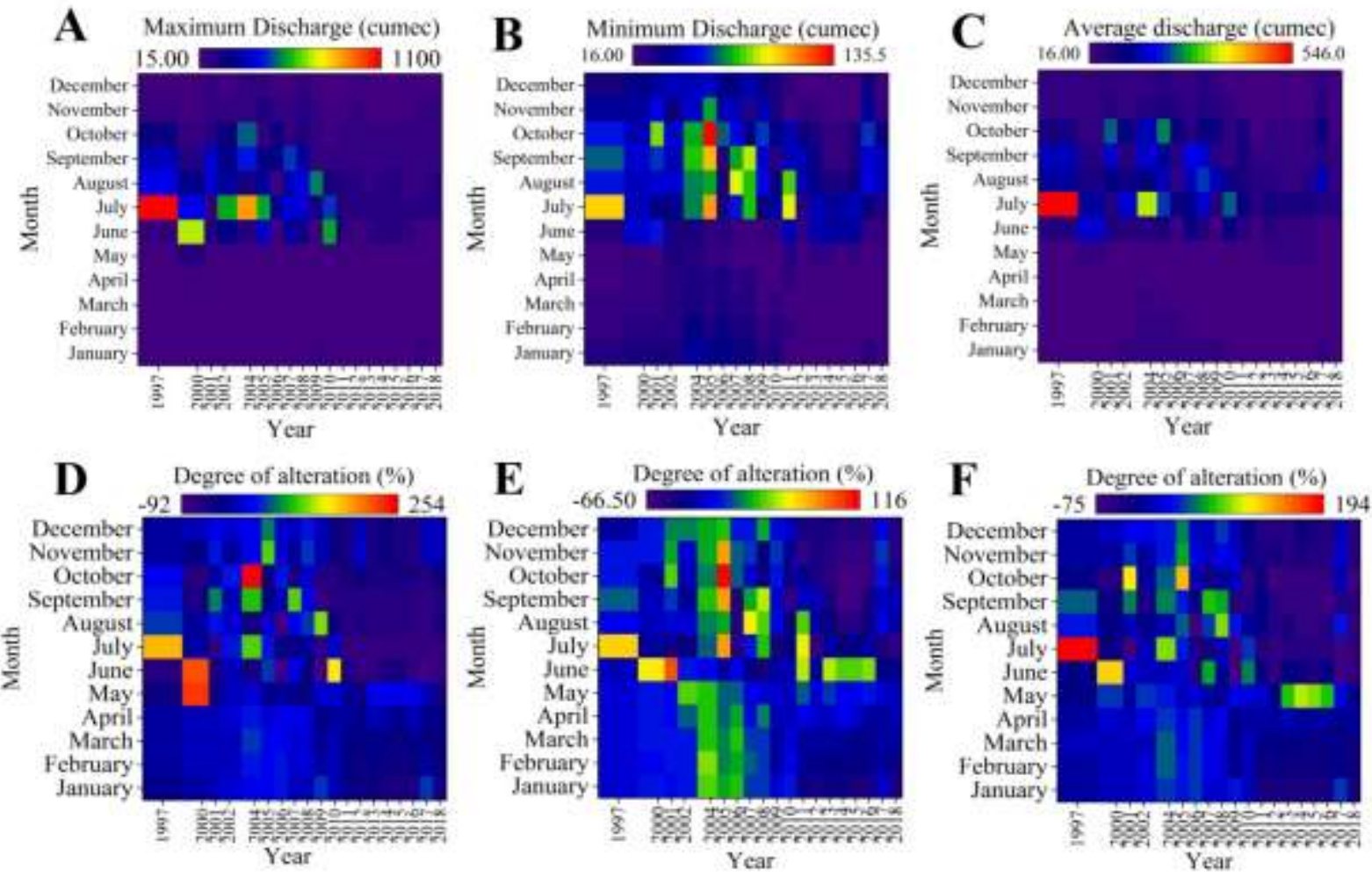

415 Figure 2: Heat map showing flow alteration about absolute maximum, minimum and average

416 discharge $(\mathrm{A}, \mathrm{B}, \mathrm{C})$ and maximum, minimum and average discharge change rate $(\mathrm{D}, \mathrm{E}, \mathrm{F})$. Here 4172012 is the damming year.

418 From the heat map of maximum, minimum and average discharge, and discharge change rate, it 419 is very evident that in the pre-dam period discharge anomaly (positive and negative) is 420 accountable for but its dynamics were highly observable in case of minimum discharge 421 specifically in the monsoon months. After damming, the sharp decline of discharge without any 422 incident of the anomaly was noticed (Fig. 2A, B, C). Similarly, the rate of discharge attenuation 423 was found in post-dam conditions. For instance, it was up to $92 \%, 66.5 \%$, and $75 \%$ in case of 
424 maximum, minimum and average discharges respectively (Fig. 2D, E, F). Such change was 425 recognized more during monsoon months. Discharge increment rate was also recorded in these 426 heat maps, however; all such incidents were identified in the pre-dam period. It does mean there 427 were many years when maximum, minimum, and average discharge was greater than that of 428 respective average.

\section{$429 \quad 5.2$ Periodicity Analysis}

430 The continuous wavelet power spectrum of average discharge in pre-monsoon, monsoon, postmonsoon, and winter seasons was presented in figure 3. After damming (2012), significant 432 periodicity in the wavelet power spectrum was identified in 3-5 years' band particularly in different seasons. From the wavelet power spectrum, the highest power (represents the variance 434 of flow) was found near the bands of 3-4 years from 2012 to 2015. It does signify that the nature 435 of river flow was changed more or less in the same direction with quite varying magnitude. In the pre-monsoon season, a strong power is recognized in 2-3 years' time band from 2012 to 2015 437 (Fig. 3). In the monsoon season, a few strong wavelet power spectrums were displayed in 2-8 438 years' band from 2000 to 2009; in 16-30 years' band from 2012 to 2017 (Fig. 3b). In the postmonsoon season, three significant spectrums were noticed. Among them, a comparatively 440 stronger significant spectrum was found in the 2-2.8 years' band from 1995 to 2000,4 to 7 years' 441 band from 2012 to 2015 (Fig. 3c). During the winter season, a few strong spectrums were 442 portrayed after 2012.
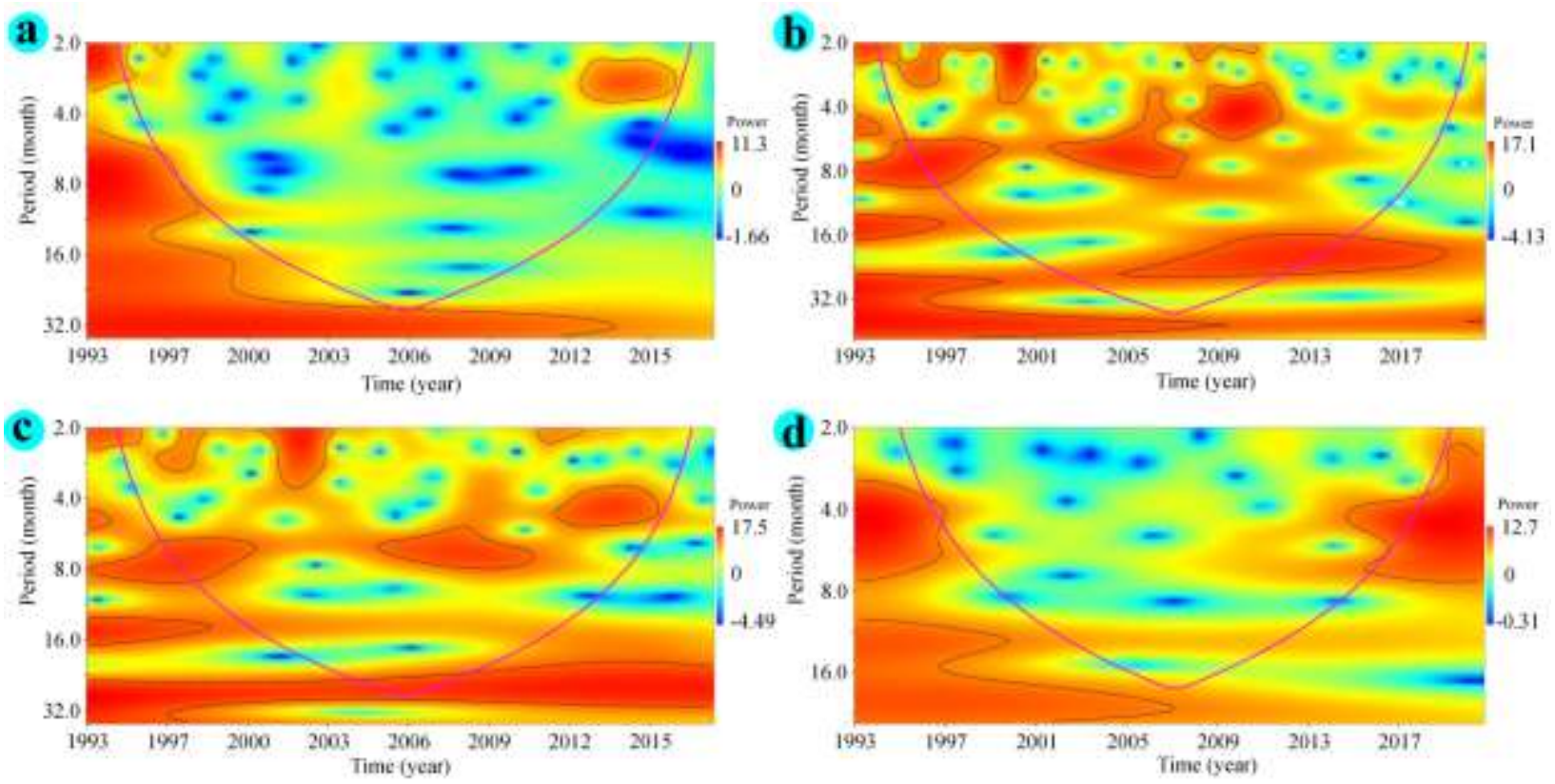
444 Fig. 3 (a - d) Continuous wavelet power spectrum of average flow data from 1992 to 2018 445 recorded at Joda Bridge Gauge station over Atreyee river for (a) Pre-monsoon (b) Monsoon (c) 446 Post-monsoon and (d) Winter season. Red and blue represent stronger and weaker powers 447 respectively. A thick black contour line delineates a $5 \%$ significance level against the red noise. 448 Conic concave area (border by pink color) shows the cone of interest within which significance 449 could be judged

\section{$450 \quad 5.3$ Hydrological modification of wetland}

\section{$451 \quad$ 5.3.1 Modification about individual hydrological components}

452 Figure 4 (A) shows the hydrological components of the wetlands like hydro-duration, WPF, and 453 water depth. Each map was sub-classed and the area under each was documented in table 2. 454 About the hydro-period, the absolute area under longer hydro-duration ( $>9$ months) was reduced 455 from 69.04 to $42.81 \mathrm{~km}^{2}$ in between pre and post-dam periods. however, in terms of the 456 proportion of area, there was no significant change. The hydro-period below three months also 457 shows the significant reduction of the area indicating the improvement of hydrological state but 458 practically since the larger extent of area under this was completely obliterated in the post-dam 459 period. The same trend was also noticed in the case of WPF. Low WPF $(<33 \%)$ zone was 460 squeezed from $743.12 \mathrm{~km}^{2}(68.44 \%)$ to $332.57 \mathrm{~km}^{2}(60.89 \%)$ in between pre and post-dam 461 periods (Table 2). High WPF was noticed slightly increased from $1.59 \%$ to $4.14 \%$. In the case of 462 water depth, a significant increase (48.94\% to $79.26 \%)$ of the proportion of wetland area was 463 noticed in the low water depth class $(<2 \mathrm{~m})$ and a decrease in high depth $(>3 \mathrm{~m}$.) was observed. 464 High depth class area was declined from $\left(371.31 \mathrm{~km}^{2}\right) 34.70 \%$ to $\left(10.49 \mathrm{~km}^{2}\right) 1.92 \%$. Some 465 areas were recognized where water depth was recorded low but despite having relatively greater

466 WPF and hydro-period. These areas may be highly susceptible to hydrological transformation in 467 the coming days. Figure 4 portrays that areas under each hydro-period, WPF, water depth sub468 class was substantially decreased in the post-dam period. 

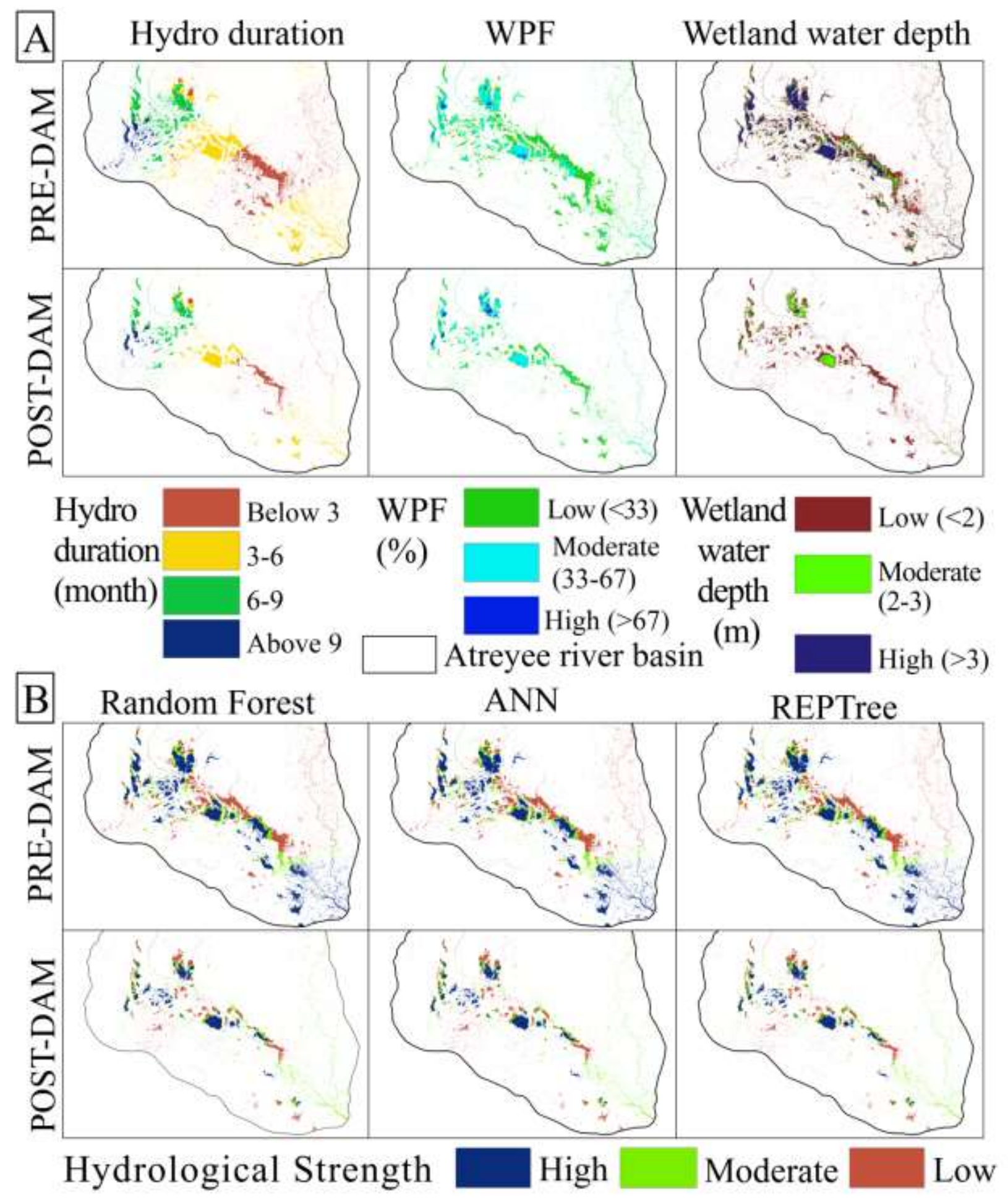

Figure 4: (A) Hydrological components of wetland like hydro-period, WPF, and water depth (B)

471 hydrological strength state models using different ML models for both pre and post-dam periods 
474 Table 2: Area under different parameters used for identification hydrological strength of the 475 wetland

\begin{tabular}{|c|c|c|c|c|}
\hline Parameters & Period & $\begin{array}{c}\text { Parameter } \\
\text { sub-class }\end{array}$ & Area in $\mathbf{k m}^{2}$ & $\%$ of area \\
\hline \multirow{8}{*}{ Hydro-period (month) } & \multirow{4}{*}{ Pre-dam } & Below 3 & 299.83 & 28.02 \\
\hline & & 3 to 6 & 477.11 & 44.58 \\
\hline & & 6 to 9 & 224.22 & 20.95 \\
\hline & & Above 9 & 69.04 & 6.45 \\
\hline & \multirow{4}{*}{ Post-dam } & Below 3 & 114.86 & 21.03 \\
\hline & & 3 to 6 & 235.58 & 43.13 \\
\hline & & 6 to 9 & 152.92 & 28.00 \\
\hline & & Above 9 & 42.81 & 7.84 \\
\hline \multirow{6}{*}{ WPF (\%) } & \multirow{3}{*}{ Pre-dam } & Low & 743.12 & 69.44 \\
\hline & & Moderate & 310.03 & 28.97 \\
\hline & & High & 17.05 & 1.59 \\
\hline & \multirow{3}{*}{ Post-dam } & Low & 332.57 & 60.89 \\
\hline & & Moderate & 191.01 & 34.97 \\
\hline & & High & 22.59 & 4.14 \\
\hline \multirow{6}{*}{$\begin{array}{l}\text { Wetland water depth } \\
\qquad(\mathrm{m})\end{array}$} & \multirow{3}{*}{ Pre-dam } & Low $(<2)$ & 523.72 & 48.94 \\
\hline & & $\begin{array}{c}\text { Moderate } \\
(2-3)\end{array}$ & 175.17 & 16.37 \\
\hline & & $\operatorname{High}(>3)$ & 371.31 & 34.70 \\
\hline & \multirow{3}{*}{ Post-dam } & Low $(<2)$ & 432.89 & 79.26 \\
\hline & & $\begin{array}{c}\text { Moderate } \\
(2-3)\end{array}$ & 102.79 & 18.82 \\
\hline & & $\operatorname{High}(>3)$ & 10.49 & 1.92 \\
\hline
\end{tabular}

\subsubsection{Modification in reference to Hydrological strength (HS) models}

478 Figure 4B shows the hydrological strength (HS) using ANN, RF, and REPTree ML models both

479 for pre and post-dam periods. High HS was widely found across the river basin covering both 480 upper and lower catchments during the pre-dam period but a huge area under this category was 481 squeezed in the post-dam period. A large part of the wetland with high HS in the lower part of 482 the basin was lost showing maximum degree of conversion. A large tract of wetland with high 483 HS astride of river was also witnessed wetland transformation from high HS to moderate and 
484 low. Table 3 depicts the area under different HS zones computed for each applied model. 485 Noticeably, it was found that the area under the high HS zone was about $47 \%$ as per all the models but it was reduced to about $32 \%$ with very little inter-model areal fluctuation. The area 487 under moderate HS zone was declined about the absolute area $\left(210 \mathrm{~km}^{2}\right.$ to $\left.187 \mathrm{~km}^{2}\right)$ however in 488 489 terms of relative area, it was increased by 14\%. The area under high HS was shifted to a moderate HS zone. Applied ML HS models showed that there was no significant variation in areal extents and geographical positions of high, moderate, and low HS zones and thus, all those models could be valid. However, conventionally, it requires validation for finding out the most suited one.

493 Table 3: Area under different Hydrological strength state categories using ML methods

\begin{tabular}{|c|r|r|r|r|r|r|}
\hline \multirow{2}{*}{$\begin{array}{c}\text { Machine learning } \\
\text { algorithms } \\
\text { applied }\end{array}$} & \multicolumn{3}{|c|}{ Pre-dam } & \multicolumn{3}{c|}{ Post-dam } \\
\cline { 2 - 7 } & Low & Moderate & High & Low & Moderate & \multicolumn{1}{c|}{ High } \\
\hline \multirow{2}{*}{ ANN } & 361.74 & 209.67 & 498.79 & 184.38 & 186.84 & 174.96 \\
& $(33.80)$ & $(19.59)$ & $(46.61)$ & $(33.75)$ & $(34.20)$ & $(32.03)$ \\
\hline \multirow{2}{*}{ RF } & 361.96 & 210.11 & 498.13 & 192.24 & 182.41 & 171.52 \\
& $(33.82)$ & $(19.63)$ & $(46.55)$ & $(35.19)$ & $(33.40)$ & $(31.40)$ \\
\hline \multirow{2}{*}{ REPTREE } & 361.89 & 209.52 & 498.79 & 185.8 & 186.9 & 173.47 \\
& $(33.82)$ & $(19.58)$ & $(46.61)$ & $(34.02)$ & $(34.22)$ & $(31.76)$ \\
\hline
\end{tabular}

494

\subsubsection{Validation of HS models}

496 From the applied statistical measures of validation, it is clear that all the applied models have an excellent agreement between map and ground conditions and therefore, could be accepted. AUC values range from 0.89 to 0.92 , sensitivity from 0.89 to 0.9 , specificity from 0.88 to 0.92 , kappa coefficient from 0.89 to 0.94 indicating the acceptability of all the models. However, to select the best representative model, a comparative analysis of those values was done and the REPTree model was recognized as the best suited since all the measures show the highest agreement (Table 4). MCC value was also found 0.82 in the case of REPTree both during pre and post-dam periods and this value is greater than MCC produced by the other models.

504 Table 4: Accuracy result of the wetland hydrological strength models using ML algorithm

\begin{tabular}{|c|c|c|c|c|c|c|}
\hline Phases & Models & $\begin{array}{c}\text { AUC } \\
\text { (ROC) }\end{array}$ & Sensitivity & Specificity & MCC & $\begin{array}{c}\text { Kappa } \\
\text { coefficient (K) }\end{array}$ \\
\hline
\end{tabular}




\begin{tabular}{|c|l|c|c|c|c|c|}
\multirow{5}{*}{ Pre-dam } & REPTree & 0.91 & 0.9 & 0.92 & 0.82 & 0.91 \\
\cline { 2 - 7 } & RF & 0.90 & 0.89 & 0.92 & 0.81 & 0.90 \\
\cline { 2 - 7 } & ANN & 0.91 & 0.89 & 0.88 & 0.78 & 0.89 \\
\hline \multirow{3}{*}{ Post-dam } & REPTree & 0.92 & 0.9 & 0.92 & 0.82 & 0.94 \\
\cline { 2 - 7 } & RF & 0.9 & 0.89 & 0.92 & 0.81 & 0.92 \\
\cline { 2 - 7 } & ANN & 0.89 & 0.89 & 0.88 & 0.78 & 0.92 \\
\hline
\end{tabular}

\subsection{Modification in reference to lateral hydrological connectivity}

507 Flood water, flow of river water tie channel, groundwater flow connects the wetland with the 508 river (Tootchi et al., 2019; Yabusaki et al., 2020). Disconnection of some wetlands from lateral 509 flood spread limit deteriorates the water supply to the wetland. Figure 5 A and B respectively 510 represent the active inundation zones with possible floodwater depth in pre and post-dam periods 511 in the wetland domain. From the illustration, it is quite clear that the active inundation area in the

512 pre-dam period was considerably greater than the post-dam period. In the pre-dam period, the 513 inundation area was $4827.82 \mathrm{~km}^{2}$ which was reduced to $1627.30 \mathrm{~km}^{2}$ in the post-dam period. 514 Depth of floodwater ranged from 0 to $17 \mathrm{~m}$. in pre-dam and 0 to $8 \mathrm{~m}$. in post dam period. This 515 incident is directly linked with the dwindling of discharge and water level in the Atreyee river. 516 Spilling of the riverbank and rainfall are two major reasons behind rainfall in the flood plain 517 region. Pal et al. (2022) also identified the same declining trend of active inundation and area and 518 water depth in the post-dam period. River astride wetlands was also witnessed considerable 519 attenuation of water level and this led to reduction of inundated area. 

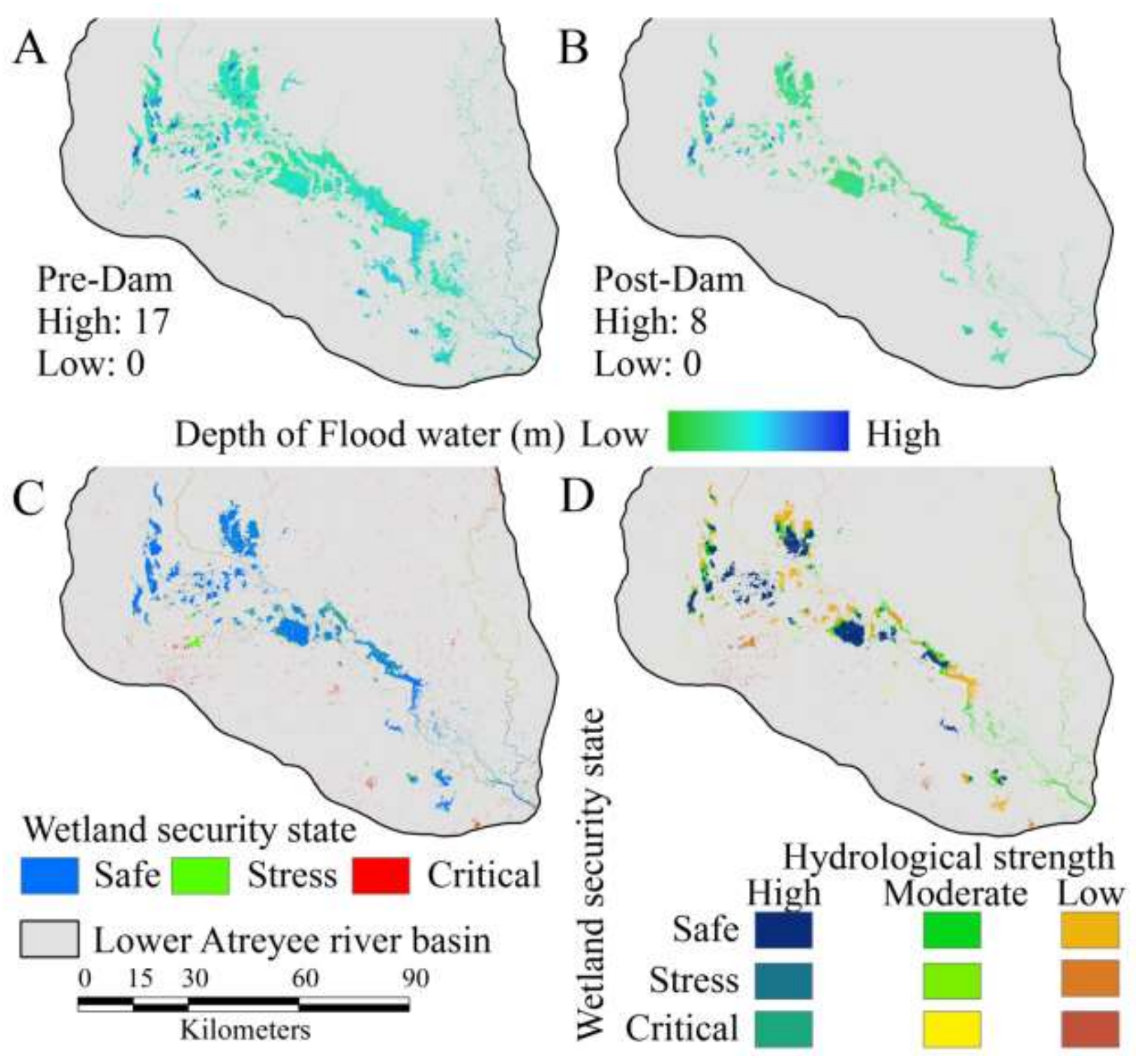

521 Figure 5: Active inundation floodplain models of (A) pre-dam (B) post-dam periods (C) wetland

522 hydrological security state (WSS) about the active inundation limits (D) wetland matrix of WSS

523 and HS showing HS under different WSS zones

\subsection{Wetland hydrological security state (WSS) concerning inundation}

525 Based on the active inundation zones of the pre and post-dam period, the wetland was 526 categorized into safe, stress and critical, and definitions of each were mentioned in the concerned 527 method section. About the lateral flood water connectivity, $85.74 \mathrm{~km}^{2}(18.79 \%), 100.72 \mathrm{~km}^{2}$ $528(22.07 \%)$, and $359.72 \mathrm{~km}^{2}(78.85 \%)$ of wetland areas of the present time were classified into 


\begin{tabular}{|c|c|c|c|}
\hline \multirow{2}{*}{$\begin{array}{l}\text { Wetland hydrological } \\
\text { security state (WSS) }\end{array}$} & \multirow{2}{*}{$\begin{array}{l}\text { Hydrological strength } \\
\text { (HS) }\end{array}$} & \multicolumn{2}{|c|}{ Area in post-dam period } \\
\hline & & Area in $\mathbf{k m}^{2}$ & Area in $\%$ \\
\hline \multirow{3}{*}{ Safe } & High & 144.84 & 26.52 \\
\hline & Moderate & 96.36 & 17.64 \\
\hline & Low & 118.52 & 21.70 \\
\hline \multirow{3}{*}{ Stress } & High & 21.02 & 3.85 \\
\hline & Moderate & 43.37 & 7.94 \\
\hline & Low & 36.33 & 6.65 \\
\hline \multirow{3}{*}{ Critical } & High & 7.60 & 1.39 \\
\hline & Moderate & 47.26 & 8.65 \\
\hline & Low & 30.88 & 5.65 \\
\hline
\end{tabular}

critical, stress and safe wetland security. Wetland away from the main river was recognized as critical due to the linkage of floodwater (Fig. 5C).

\subsection{Hydrological strength in wetland hydrological security zone (WSS and HS matrix)}

For further discrimination of wetland characters, the hydrological strength of existing wetland under different WSS zones was featured to know that how are the wetland without having lateral inundation water connectivity. Table 5 explains the HS character in different WSS zones. Usually, it was hypothesized that critical and stress WSS zone will have poor HS and safe WSS zone will have a high HS state with a greater proportion. Out of a total $85.74 \mathrm{~km}^{2}$ wetland under the critical WSS zone, $78.14 \mathrm{~km}^{2}$ was characterized by low and moderate HS. In the stress, the WSS zone total area was $100.72 \mathrm{~km}^{2}$, out of which $79.7 \mathrm{~km}^{2}$ fall under the low and moderate HS zone (Table 5). On the other hand, out of a total $359.72 \mathrm{~km}^{2}$ wetland in the safe WSS zone, $40.26 \%$ wetland was characterized by a high HS state. The findings of the present WSS and HS matrix satisfied the adopted hypothesis.

Table 5: Hydrological strength of wetland in different hydrological security states. The computed area under each zone is given in the table

Note: Wetland hydrological security state was determined based on lateral inundation connectivity and hydrological strength was determined based on hydrological components like WPF, HP and water depth 


\subsection{Morphological change of wetland}

549 Figure 6 depicts the wetland fragmentation status in pre and post-dam periods. From the figure, it is very clear that there was well defined long wetland tract alongside the main river during the

551 pre-dam period. In the post-dam period, most of the continuous large wetland tract was found

552 fragmented. For instance, In the pre-dam period, $10.84 \%$ and $22.03 \%$ areas were under patch and

553 edge area respectively but these were inflated during the post-dam period (patch and edge areas

554 are $22.21 \%$ and $27.43 \%$ ) signifying enhancement of adverse situation of wetland morphology.

555 Contrarily, the large core area was reduced from $52.11 \%$ to $33.71 \%$ in between pre-and post-dam

556 periods (Table 6). Growing fragmentation means increasing edge-area ratio which leads to the 557 enhancement of anthropogenic intervention (Shen et al., 2019; Kundu et al., 2021). Such change 558 is not only the alteration of landscape morphology, but it can adversely affect the serviceability 559 of such precious natural capital (Lu et al., 2019).
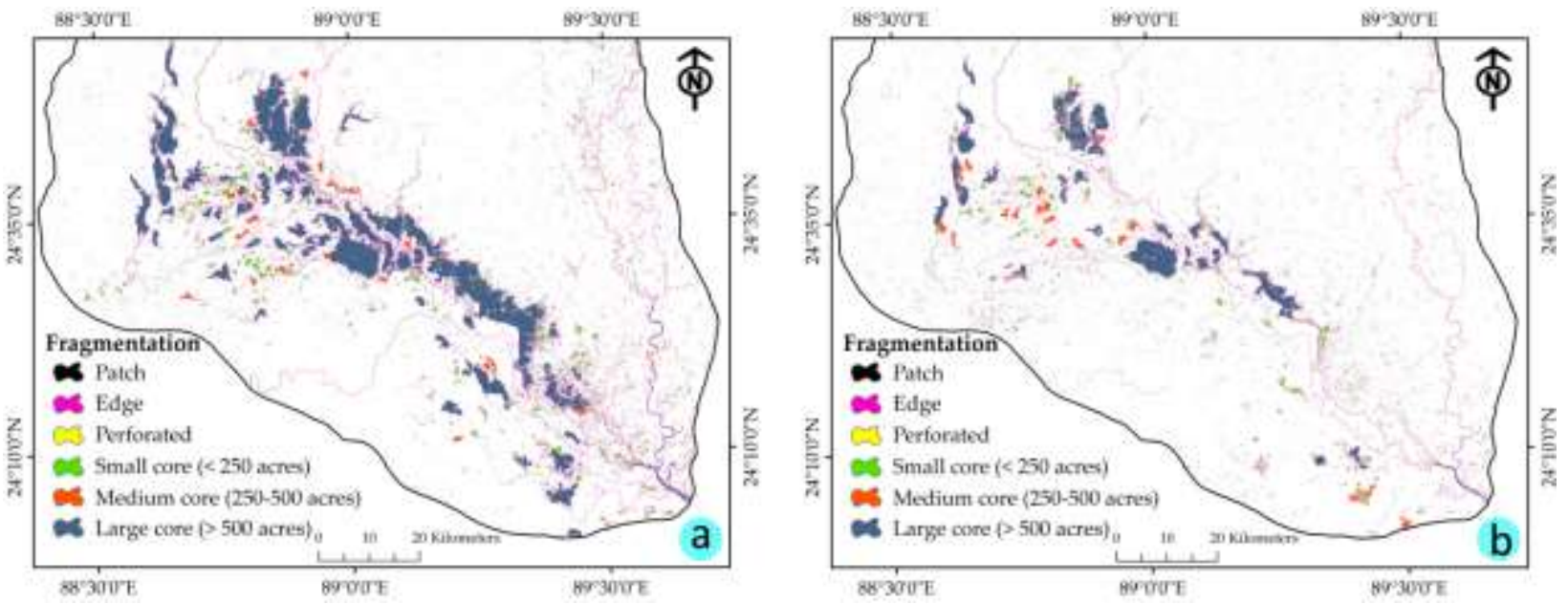

561

Figure 6. Wetland fragmentation showing patch, edge, perforated, small, medium, and large cores of (a) pre-dam and (b) post-dam periods

563

564

Table 6: Proportion of area of landscape fragmentation for the post-monsoon season in pre and 565 post-dam periods

\begin{tabular}{|c|c|c|}
\hline \multirow{2}{*}{$\begin{array}{c}\text { Landscape } \\
\text { Fragmentation }\end{array}$} & \multicolumn{2}{|c|}{ Wetland condition in post-monsoon seasons } \\
\cline { 2 - 3 } & Pre-dam & Post-dam \\
\cline { 2 - 3 } & Area $\left(\mathbf{k m}^{\mathbf{2}}\right)$ & Area $\left(\mathbf{k m}^{\mathbf{2}}\right)$ \\
\hline Patch & $116.01(10.84 \%)$ & $121.30(22.21 \%)$ \\
\hline Edge & $235.77(22.03 \%)$ & $149.81(27.43 \%)$ \\
\hline
\end{tabular}




\begin{tabular}{|c|c|c|} 
Perforated & $15.30(1.43 \%)$ & $10.87(1.99 \%)$ \\
\hline Low core & $122.32(11.43 \%)$ & $64.23(11.76 \%)$ \\
\hline Medium core & $22.80(2.13 \%)$ & $15.68(2.87 \%)$ \\
\hline Large core & $557.68(52.11 \%)$ & $184.11(33.71 \%)$ \\
\hline
\end{tabular}

\subsection{Identifying associated modification in some specific cases}

568 Ten wetlands from different parts of the study unit as mentioned in figure 1 were taken for 569 showing hydrological modification and associated other changes and their current trend (Figure

570 7). Driver-specific analysis endorsed the following findings like flow modification impact was 571 high to moderate in maximum wetlands and driver's current trend at $60 \%$ cases were found 572 increasing and $40 \%$ cases the impact was continued as observed earlier. Inundation frequency 573 was found to decrease in most of the cases, inundation magnitude was found to decrease or 574 remain as usual. In association with those hydrological transformations, agricultural 575 encroachment, construction activities, water pollution, eutrophication, habitat change, 576 biodiversity loss, etc. were found degraded in most of the selected wetlands. Hydrological 577 strength is fundamental to an aquatic ecosystem (Meng et al., 2020; Li et al., 2021). Since the 578 wetlands witnessed the adverse impact of hydrological transformation, often promoted some 579 other associated causes like habitat quality change, water pollution, biodiversity loss, etc. Some 580 people residing near wetland areas also reported that after shallowing wetlands, inconsistence 581 water appearance in wetland, people received an opportunity to convert the wetland into 582 perennial agriculture land. 


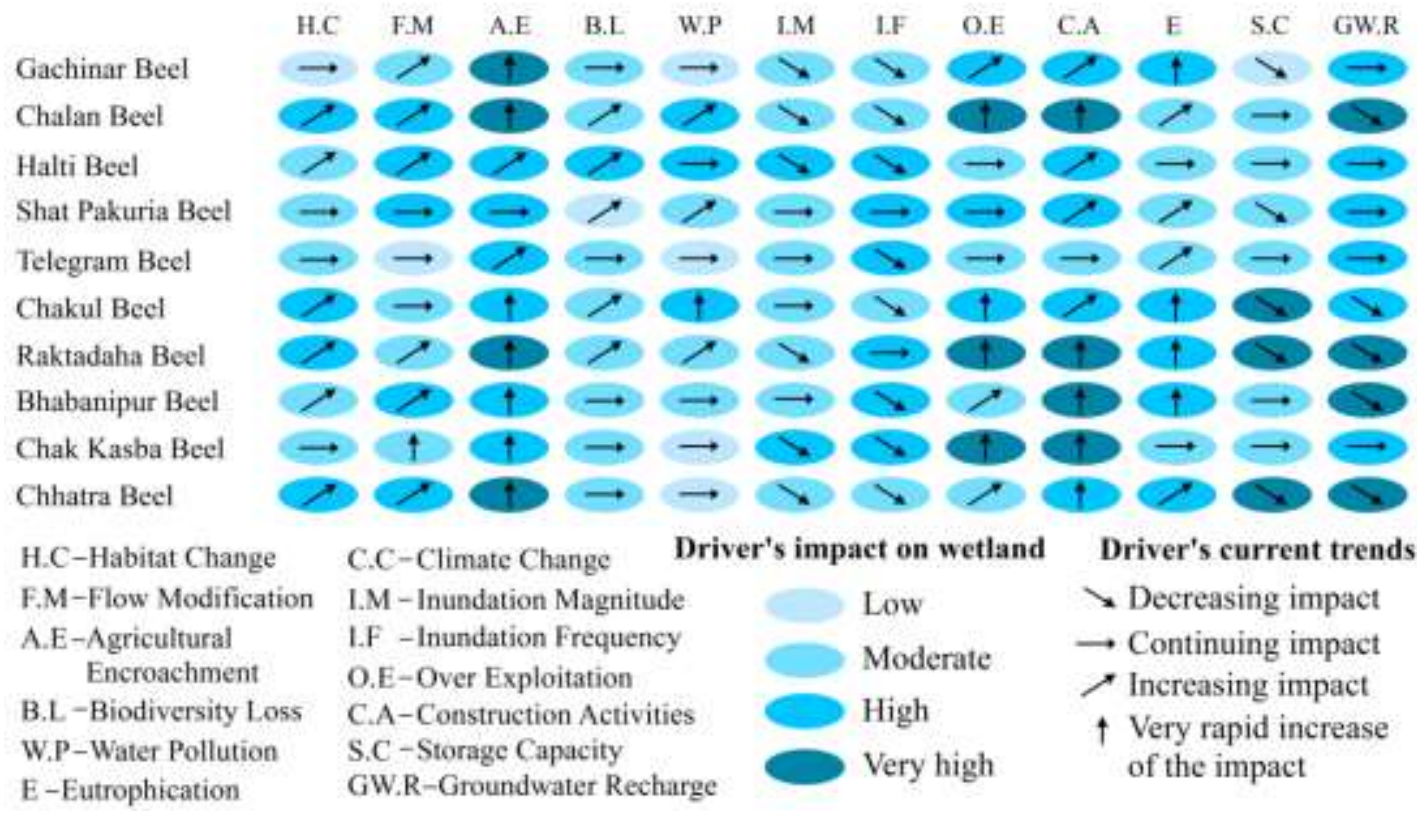

584 Figure: 7 Current trends and degree of driver's impact on the wetland of Atreyee river basin

585 6. Discussion

586 From the result, it is very clear that damming brought a landmark hydrological change in the 587 river and riparian wetlands. The squeeze of active inundation plain impacted adversely to the 588 wetland hydrological security. Poor hydrological strength was detected in critical and stress 589 wetland insecurity zones. About $48.97 \%$ wetland area was wiped out after damming. A large 590 tract of the wetland along the confluence segment of the main river at its proximity also 591 hydrologically weakened. Now the questions how the hydrological modification, wetland loss is 592 related to river flow modification?

593 Discharge attenuation after damming was well reported in this paper and this finding is 594 supported by similar works conducted by Zheng et al. (2019), Amenuvor et al. (2020), Chen et 595 al. (2021), Gao et al. (2021) across the world. The rate of attenuation depends on the degree of 596 anthropogenic control as reported by Fleischmann et al. (2019). Pal (2016b) investigated 597 hydrological modification in the Atreyee river and reported that average flow was reduced by $59853 \%$, reduced overall flood frequency, and flood magnitude above extreme danger level was 599 attenuated by $46 \%$. Talukdar and Pal (2020) also documented the same trend of extreme 600 hydrological change in the Punarbhaba river of Barind plain.

601 Since the flood plain wetlands are fed by rain and floodwater, the dynamics of the flood of a 602 river are strongly linked with riparian flood plain (Fritz et al., 2018; Vidon et al., 2019; Alafifi 
and Rosenberg, 2020; Cui et al., 2021). Lowering of floodwater level in Atreyee river during monsoon season was identified as a prime reason behind the reduction of the active flood plain. Rainfall reduction $(28.76 \%$ ) was also identified inflow availability in river and wetland reduction (Pal et al., 2022) and it is also a reason behind active flood plain squeeze. Embanking rivers and restricting discharge up to an artificially elevated level also is a major cause behind less spread flood water laterally (Galib et al., 2018; Sarkar et al., 2020). But if the embankment is breached anyway, it may cause the sudden spread of water laterally obliterating the natural and manmade infrastructures (Urzică et al., 2021). It can adversely affect the wetland hydrological stability and associated ecology. Since the water level was attenuated and the increased volume of water during extreme depression during monsoon was capacitated by the raised embankment, flood severity except during breach time was found weak. It is a well-explored cause for active flood plain squeeze. Mondal and Pal (2018) also reported an active flood plain squeeze incident in the Mayurakshi river basin of Eastern India.

As a result of this squeeze of the active floodplain during the post-dam period, a good proportion of wetland was left beyond the present flood spread limit and these wetlands were started to suffer from water scarcity, paucity of nutrients, fish seeds, and so on. Flood water supply at a regular interval not only makes the wetland hydrologically secure but also ecologically efficient. For instance, free nutrient and fish seed supply reduces the cost of fishing and thereby supports the livelihood of the fishermen. The concentration of chemical fertilizers, pesticides residues within wetlands leads to a great ecological threat (Quintela et al., 2020) like strengthening exotic species growth and arresting the growth of valuable endemic species (Maurya et al., 2019). Regular flooding can remove such noxious residues and refresh the wetland habitat (Liu et al., 2018). Considering mainly water service of flooding, the wetlands were categorized into safe, stress, and critical. Critical wetlands are not used to receive floodwater since from pre-dam period and they are solely dependent on rainwater and seepage water. Lowering groundwater tables and lessening rainfall (Pal et al., 2022) are therefore threats to the critical WSS. In the stress WSS zone, floodwater is usually not received but rarely received. So, the wetland within this zone is not hydrologically rich and ecologically prudent. Wetland within a safe zone receives regular flood water and nutrients and therefore, is hydro-ecologically efficient. This sort of wetland classification was also done by Talukdar and Pal (2020). 
Analysis of HS models identified that a large part of the wetland within critical and stress WSS zones suffer from hydrological weakness. For instance, inconsistent water appearance, narrow hydro-period, shallow water depth were identified in these zones. Hydrological strength is considerably better in the safe WSS zone. However, all parts of the wetlands are not hydrologically stronger, some wetlands in very proximity to the main river within this zone were identified hydrologically sick and it is in fact due to the erection of an embankment astride the main river restricting natural flooding. In some cases, tie channels that connect river and wetland water were also reclaimed mainly for agriculture purposes (Mukherjee et al., 2018; Pal and Talukdar, 2019). Case studies from the present study area also proved the loss of tie channels and hydrological degradation. Pal and Talukdar (2019), Saha and Pal (2019) also reported hydroecological deterioration of wetland due to tie channel loss. Some tie channels were identified those were not reclaimed but their aggraded bed level at the off-take points is quite above the normal water level, so they rarely get support from river discharge. These situations led to hydrological degradation of river proximate wetland despite tie channel linking.

Lowering water availability in wetland, irregular water appearance for a short time often invites agrarian people to invade the wetland. Initially, they used such area for seasonal cultivation but gradually, they make it suitable for perennial agriculture land effacing its wetland characters (Wondie, 2018). Often agriculture invasion is condemned as the most dominant cause behind wetland loss in the flood plain region (Saha and Pal, 2019). Das and Pal (2018), Saha and Pal (2019), Sarda and Pal (2021a) rightly pointed out hydrological deterioration can also promote this vector. It may also promote the expansion of the built-up area since the study region is densely populated. The increasing population demands more habitats for living. Often people reclaim this land without considering its priceless serviceability. If such land is public, the rate of reclamation is quite greater. All these are caused for the morphological transformation of wetlands (Pal et al., 2022) as also found in this present study. Patch and edge dominated areas were increased and the large core area was decreased in this present case. Increasing the edge area ratio after growing fragmentation exerts extra pressure on wetland habitat and ecology (Mukherjee and Pal, 2021). This trend of morphological wetland scape transformation is commonly found across the world (Shen et al., 2019; Cui et al., 2021; Das et al., 2021; Kundu et al., 2021). 
For exploring hydrological change in wetland, image-driven hydrological components were used for overcoming the issues of spatial scale data scarcity. Image-driven pixel scale hydro-period, depth, and WPF data derivation is very useful for hydrological modeling over wider geographical area time and cost-effectively. The approaches taken here for data derivation would be much more refined and the resolution of the used images would be finer. In this regard, more research is required. One or two hydrological monitoring stations at wetland is not just enough to build a spatial hydrological strength model. So, it is now the chief alternative to fill the fieldbased data deficiency. Machine learning algorithms were applied for building the HS models to resolve the complex spatial relationship among the parameters and use the robustness of the models. Al-Abadi and Al-Najar (2020), Costache and Bui (2020), Pal and Paul (2020), Pal and Sarda (2021) recommended ML models over other statistical models. A multi-model approach was taken for justifying the best-suited model. Multiple statistical tests were applied for verifying the suitability of the model. If all the applied statistical test results figure out the suitability of a model, its acceptability will be very strong. In this study, REPTree was found as the best suited confirmed by all the test results. WSS and HS matrix is a new way for featuring wetland coupling inundation connectivity and current wetland hydrological conditions. This matrix yielded nine wetland types with the specific nature of WSS and HS.

\section{Conclusion}

From the result, it is very evident that damming was a major determinant of river flow and in consequence of the attenuation of river flow, the active flood plain region was squeezed by $66.29 \%$ curtailing the water supply to the wetlands away from the current active flood plain limit. Flow alteration also leads to loss of extensive wetland area and existing wetland was also witnessed remarkable hydrological alteration. Hydrological strength models exhibited that area under high HS state was substantially reduced inflating area under relatively weaker HS state zones. Integrated analysis of wetland hydrological security state (WSS) based on lateral flood water connectivity and hydrological strength (HS) categories revealed that critical and stress WSS zones recorded relatively poor HS. Weakening hydrological strength was also identified as a major reason behind promoting wetland fragmentation as was noticed after damming in the present study.

The result itself is a vital instrument for wetland management and restoration. Reduction of flow is the primary reason behind attenuation of flood spread and squeezing flood water spread is 
caused for enhancing wetland hydrological insecurity state. So, to formulate sustainable wetland management and restoration strategies, it is very essential to release the ecologically viable amount of water to the dam downstream segment. It can only revive the river and riparian wetland ecology. It can also help to restore the wetlands left beyond lateral hydrological connectivity.

Since the work clearly mapped the active flood plain zones after damming incidents and recognized wetland within and beyond, it would be a good instrument for adopting priority basis planning. Moreover, since the study further explored poor hydrological strength (HS) states within critical and stress WSS zones, flood restoration is an effective option to improve hydrological efficacy and wetland security. Maintaining water levels would be a panacea to resolving the ongoing and upcoming crisis. Detail study is further required for setting a viable amount of water flow that is to be released downstream. The study successfully linked the alteration in river flow and hydrological conditions of the wetland applying an integrated advanced hydrological modeling approach. This work would also be a good guide regarding the exploration of image-based pixel scale hydrological data resolving spatial scale wetland hydrological data scarcity. These are the novel contribution of this paper. However, adopting the same approach or more updated approach, high spatial and temporal resolution data could provide better output. Moreover, for analyzing the hydrological security of wetland, only inundation connectivity was focused but tie channel connectivity, groundwater support in terms of vertical hydrological connectivity were not taken into consideration. Because of spatial scale data non-availability, these were not taken but the inclusion of all these could yield more authentic results on wetland hydrological alteration.

\section{Acknowledgments}

The corresponding author of this article (Rajesh Sarda) would like to acknowledge University Grants Commission (UGC Ref. No.: 3430/(NET-DEC 2018)), New Delhi, India for providing financial support as a Junior Research fellowship to conduct the research work presented in this paper. We would like to extend my gratitude to USGS for providing Landsat imageries. 


\section{References}

Adel, M.M., 2013. Upstream water piracy, the strongest weapon of cornering a downstream nation. Environment and Ecology Research, 1(3), pp.85-128.

Aghsaei, H., Dinan, N.M., Moridi, A., Asadolahi, Z., Delavar, M., Fohrer, N. and Wagner, P.D., 2020. Effects of dynamic land use/land cover change on water resources and sediment yield in the Anzali wetland catchment, Gilan, Iran. Science of the Total Environment, 712, p.136449.

Al-Abadi, A.M. and Al-Najar, N.A., 2020. Comparative assessment of bivariate, multivariate and machine learning models for mapping flood proneness. Natural Hazards, 100(2), pp.461491.

Alafifi, A.H. and Rosenberg, D.E., 2020. Systems modeling to improve river, riparian, and wetland habitat quality and area. Environmental Modelling \& Software, 126, p.104643.

Ali, R., Kuriqi, A., Abubaker, S. and Kisi, O., 2019. Hydrologic alteration at the upper and middle part of the Yangtze river, China: towards sustainable water resource management under increasing water exploitation. Sustainability, 11(19), p.5176.

Amenuvor, M., Gao, W., Li, D. and Shao, D., 2020. Effects of Dam Regulation on the Hydrological Alteration and Morphological Evolution of the Volta River Delta. Water, 12(3), p.646.

Arabameri, A., Santosh, M., Saha, S., Ghorbanzadeh, O., Roy, J., Tiefenbacher, J.P., Moayedi, H. and Costache, R., 2021. Spatial prediction of shallow landslide: application of novel rotational forest-based reduced error pruning tree. Geomatics, Natural Hazards and Risk, 12(1), pp.13431370.

Arévalo-Mejía, R., Leblois, E., Salinas-Tapia, H., Mastachi-Loza, C.A., Bâ, K.M. and DíazDelgado, C., 2020. A baseline assessment of hydrologic alteration degree for the Mexican catchments at gauged rivers (2016). Science of The Total Environment, 729, p.139041.

Barter, R.L. and Yu, B., 2018. Superheat: An R package for creating beautiful and extendable heatmaps for visualizing complex data.Journal of Computational and Graphical Statistics, 27(4), pp.910-922. 
751 Bouramtane, T., Kacimi, I., Bouramtane, K., Aziz, M., Abraham, S., Omari, K., Valles, V., 752 Leblanc, M., Kassou, N., El Beqqali, O. and Bahaj, T., 2021. Multivariate Analysis and Machine 753 Learning Approach for Mapping the Variability and Vulnerability of Urban Flooding: The Case 754 of Tangier City, Morocco. Hydrology, 8(4), p.182.

755 Bregoli, F., Crosato, A., Paron, P. and McClain, M.E., 2019. Humans reshape wetlands: 756 Unveiling the last 100 years of morphological changes of the Mara Wetland, Tanzania. Science 757 of the Total Environment, 691, pp.896-907.

758 Chakraborty, R., Talukdar, S., Basu, T. and Pal, S., 2018. Habitat identity crisis caused by the 759 riparian wetland squeeze in Tangon River Basin, Barind Region, India. Spatial Information 760 Research, 26(5), pp.507-516.

761 Chen, W., Hong, H., Li, S., Shahabi, H., Wang, Y., Wang, X. and Ahmad, B.B., 2019. Flood 762 susceptibility modelling using novel hybrid approach of reduced-error pruning trees with 763 bagging and random subspace ensembles. Journal of Hydrology, 575, pp.864-873.

764 Chen, L., Wu, Y., Xu, Y.J. and Zhang, G., 2021. Alteration of flood pulses by damming the 765 Nenjiang River, China-Implication for the need to identify a hydrograph-based inundation 766 threshold for protecting floodplain wetlands. Ecological Indicators, 124, p.107406.

767 Cheng, J., Xu, L., Wang, X., Jiang, J. and You, H., 2018. Assessment of hydrologic alteration 768 induced by the Three Gorges Dam in Dongting Lake, China. River Research and 769 Applications, 34(7), pp.686-696.

770 Costache, R. and Bui, D.T., 2020. Identification of areas prone to flash-flood phenomena using 771 multiple-criteria decision-making, bivariate statistics, machine learning and their 772 ensembles. Science of The Total Environment, 712, p.136492.

773 Cui, G., Liu, Y. and Tong, S., 2021. Analysis of the causes of wetland landscape patterns and 774 hydrological connectivity changes in Momoge National Nature Reserve based on the Google 775 Earth Engine Platform. Arabian Journal of Geosciences, 14(3), pp.1-16.

776 Das, R.T. and Pal, S., 2018. Investigation of the principal vectors of wetland loss in Barind tract 777 of West Bengal. GeoJournal, 83(5), pp.1115-1131. 
Das, S., Adhikary, P.P., Shit, P.K. and Bera, B., 2021. Urban wetland fragmentation and ecosystem service assessment using integrated machine learning algorithm and spatial landscape analysis. Geocarto International, pp.1-19.

Deforet T, Marmonier P, Rieffel D, Crini N, Giraudoux P, Gilbert D. 2009. Do parafluvial zones have an impact in regulating river pollution? Spatial and temporal dynamics of nutrients, carbon, and bacteria in a large gravel bar of the Doubs River (France). Hydrobiologia. 623(1):235-250.

Du, J., Wu, X., Wang, Z., Li, J. and Chen, X., 2020. Reservoir-Induced Hydrological Alterations Using Ecologically Related Hydrologic Metrics: Case Study in the Beijiang River, China. Water, 12(7), p.2008.

Duc, N.A., Nguyen, L.T., Thai, T.H., Khan, A., Rautenstrauch, K. and Schmidt, C., 2020. Assessing cumulative impacts of the proposed Lower Mekong Basin hydropower cascade on the Mekong River floodplains and Delta-Overview of integrated modeling methods and results. Journal of Hydrology, 581, p.122511.

Epting, S.M., Hosen, J.D., Alexander, L.C., Lang, M.W., Armstrong, A.W. and Palmer, M.A., 2018. Landscape metrics as predictors of hydrologic connectivity between Coastal Plain forested wetlands and streams. Hydrological processes, 32(4), pp.516-532.

Finlayson, C. M. (2013). Climate change and wise use of wetlands: informations from Australian wet lands. Hydrobiologia, 708(1), 145-152.

Fleischmann, A., Collischonn, W., Paiva, R. and Tucci, C.E., 2019. Modeling the role of reservoirs versus floodplains on large-scale river hydrodynamics. Natural Hazards, 99(2), pp.1075-1104.

Fritz, K.M., Schofield, K.A., Alexander, L.C., McManus, M.G., Golden, H.E., Lane, C.R., Kepner, W.G., LeDuc, S.D., DeMeester, J.E. and Pollard, A.I., 2018. Physical and chemical connectivity of streams and riparian wetlands to downstream waters: a synthesis. JAWRA Journal of the American Water Resources Association, 54(2), pp.323-345.

Gain, A.K. and Giupponi, C., 2015. A dynamic assessment of water scarcity risk in the Lower Brahmaputra River Basin: An integrated approach. Ecological indicators, 48, pp.120-131. 
805

806

807

808

809

810

811

812

813

814

815

816

817

818

819

820

821

822

823

824

825

826

827

828

829

830

Galib, S.M., Lucas, M.C., Chaki, N., Fahad, F.H. and Mohsin, A.B.M., 2018. Is current floodplain management a cause for concern for fish and bird conservation in Bangladesh's largest wetland?. Aquatic Conservation: Marine and Freshwater Ecosystems, 28(1), pp.98-114.

Gao, B.C., 1996. NDWI-A normalized difference water index for remote sensing of vegetation liquid water from space. Remote sensing of environment, 58(3), pp.257-266.

Gao, Y., Chen, L., Zhang, W., Li, X. and Xu, Q., 2021. Spatiotemporal variations in characteristic discharge in the Yangtze River downstream of the Three Gorges Dam. Science of The Total Environment, 785, p.147343.

Ge, J., Peng, W., Huang, W., Qu, X. and Singh, S.K., 2018. Quantitative assessment of flow regime alteration using a revised range of variability methods. Water, 10(5), p.597.

Ghasemain, B., Asl, D.T., Pham, B.T., Avand, M., Nguyen, H.D. and Janizadeh, S.J.V.J.O.E.S., 2020. Shallow landslide susceptibility mapping: A comparison between classification and regression tree and reduced error pruning tree algorithms. Vietnam Journal of Earth Sciences, 42(3), pp.208-227.

Greet, J., Fischer, S. and Russell, K., 2020. Longer duration flooding reduces the growth and sexual reproductive efforts of a keystone wetland tree species. Wetlands Ecology and Management, 28(4), pp.655-666.

Han, J., Kim, J., Park, S., Son, S. and Ryu, M., 2020. Seismic vulnerability assessment and mapping of Gyeongju, South Korea using frequency ratio, decision tree, and random forest. Sustainability, 12(18), p.7787.

Huang, F., Zhang, N., Guo, L.D. and Xia, Z.Q., 2016, August. Assessing the hydrologic alteration of the Yangtze River using the histogram matching approach. In IOP Conference Series: Earth and Environmental Science (Vol. 39, No. 1, p. 012002). IOP Publishing.

28 Huang, F., Li, F., Zhang, N., Chen, Q., Qian, B., Guo, L. and Xia, Z., 2017. A histogram comparison approach for assessing hydrologic regime alteration. River Research and Applications, 33(5), pp.809-822. 
831 Huang, X., Suwal, N., Fan, J., Pandey, K.P. and Jia, Y., 2019. Hydrological Alteration 832 Assessment by Histogram Comparison Approach: A Case Study of Erdu River Basin, 833 China. Journal of Coastal Research, 93(SI), pp.139-145.

834 Jeziorska, J., 2019. UAS for wetland mapping and hydrological modeling. Remote 835 Sensing, 11(17), p.1997.

836 Karim, F., Marvanek, S., Merrin, L.E., Nielsen, D., Hughes, J., Stratford, D. and Pollino, C., 837 2020. Modelling Flood-Induced Wetland Connectivity and Impacts of Climate Change and 838 Dam. Water, 12(5), p.1278.

839 Khatun, R., Talukdar, S., Pal, S. and Kundu, S., 2021. Measuring dam induced alteration in 840 water richness and eco-hydrological deficit in flood plain wetland. Journal of Environmental $841 \quad$ Management, 285, p.112157.

842 Kundu, S., Pal, S., Talukdar, S. and Mandal, I., 2021. Impact of wetland fragmentation due to 843 damming on the linkages between water richness and ecosystem services. Environmental Science 844 and Pollution Research, pp.1-20.

845 Lee, S., McCarty, G.W., Moglen, G.E., Lang, M.W., Jones, C.N., Palmer, M., Yeo, I.Y., 846 Anderson, M., Sadeghi, A.M. and Rabenhorst, M.C., 2020. Seasonal drivers of geographically 847 isolated wetland hydrology in a low-gradient, Coastal Plain landscape. Journal of $848 \quad$ Hydrology, 583, p.124608.

849 Li, D., Long, D., Zhao, J., Lu, H. and Hong, Y., 2017. Observed changes in flow regimes in the 850 Mekong River basin. Journal of Hydrology, 551, pp.217-232.

851 Li, B., Yang, Z., Cai, Y. and Li, B., 2021. The frontier evolution and emerging trends of 852 hydrological connectivity in river systems: a scientometric review. Frontiers of Earth 853 Science, 15(1), pp.81-93.

854 Liu, Z., Zhao, L., Xu, T., Bu, F., Liu, X. and Zhou, D., 2018. Quantification of potential flood 855 inundation areas in the marsh wetland of Honghe National Natural Reserve, Northeast 856 China. Ecohydrology \& Hydrobiology, 18(4), pp.355-364 
857 Lu, C., Ren, C., Wang, Z., Zhang, B., Man, W., Yu, H., Gao, Y. and Liu, M., 2019. Monitoring 858 and assessment of wetland loss and fragmentation in the Cross-boundary Protected Area: a case 859 study of Wusuli River Basin. Remote Sensing, 11(21), p.2581.

860 Maurya, P.K., Malik, D.S., Yadav, K.K., Kumar, A., Kumar, S. and Kamyab, H., 2019. 861 Bioaccumulation and potential sources of heavy metal contamination in fish species in River 862 Ganga basin: Possible human health risks evaluation. Toxicology reports, 6, pp.472-481.

863 McFeeters, S.K., 1996. The use of the Normalized Difference Water Index (NDWI) in the 864 delineation of open water features. International journal of remote sensing, 17(7), pp.1425-1432.

865 Meng, B., Liu, J.L., Bao, K. and Sun, B., 2020. Methodologies and management framework for 866 restoration of wetland hydrologic connectivity: A synthesis. Integrated environmental 867 assessment and management, 16(4), pp.438-451.

868 Milani, M., Marzo, A., Toscano, A., Consoli, S., Cirelli, G.L., Ventura, D. and Barbagallo, S., 869 2019. Evapotranspiration from horizontal subsurface flow constructed wetlands planted with 870 different perennial plant species. Water, 11(10), p.2159.

871 Mitsch, W.J. and Gosselink, J.G., 2015. Wetlands. John Wiley \& Sons.

872 Mondal, D. and Pal, S., 2018. Monitoring dual-season hydrological dynamics of seasonally 873 flooded wetlands in the lower reach of Mayurakshi River, Eastern India. Geocarto 874 International, 33(3), pp.225-239.

875 Mosavi, A., Ozturk, P. and Chau, K.W., 2018. Flood prediction using machine learning models: 876 Literature review. Water, 10(11), p.1536.

877 Mukherjee, K., Pal, S. and Mukhopadhyay, M., 2018. Impact of flood and seasonality on 878 wetland changing trends in the Diara region of West Bengal, India. Spatial Information 879 Research, 26(4), pp.357-367.

880 Mukherjee, K. and Pal, S., 2021. Hydrological and landscape dynamics of floodplain wetlands of 881 the Diara region, Eastern India. Ecological Indicators, 121, p.106961. 
882 Nampak, H., Pradhan, B. and Abd Manap, M., 2014. Application of GIS based data driven 883 evidential belief function model to predict groundwater potential zonation. Journal of 884 Hydrology, 513, pp.283-300.

885
Nhu, V.H., Shirzadi, A., Shahabi, H., Singh, S.K., Al-Ansari, N., Clague, J.J., Jaafari, A., Chen, W., Miraki, S., Dou, J. and Luu, C., 2020. Shallow landslide susceptibility mapping: A comparison between logistic model tree, logistic regression, naïve bayes tree, artificial neural network, and support vector machine algorithms. International journal of environmental research and public health, 17(8), p.2749.

Onyango, D.O. and Opiyo, S.B., 2021. Detection of historical landscape changes in Lake Victoria Basin, Kenya, using remote sensing multi-spectral indices. Watershed Ecology and the Environment.

Orimoloye, I.R., Kalumba, A.M., Mazinyo, S.P. and Nel, W., 2020. Geospatial analysis of wetland dynamics: wetland depletion and biodiversity conservation of Isimangaliso Wetland, South Africa. Journal of King Saud University-Science, 32(1), pp.90-96.

Özelkan, E., 2020. Water body detection analysis using NDWI indices derived from landsat-8 OLI. Polish Journal of Environmental Studies, 29(2), pp.1759-1769.

Pal, S., 2016a. Impact of Massanjore dam on hydro-geomorphological modification of Mayurakshi river, Eastern India. Environment, development and sustainability, 18(3), pp.921944.

Pal, S., 2016b. Impact of water diversion on hydrological regime of the Atreyee river of IndoBangladesh. International Journal of River Basin Management, 14(4), pp.459-475.

Pal, S. and Saha, T.K., 2018. Identifying dam-induced wetland changes using an inundation frequency approach: The case of the Atreyee River basin of Indo-Bangladesh. Ecohydrology \& Hydrobiology, 18(1), pp.66-81.

Pal, S. and Talukdar, S., 2019. Impact of missing flow on active inundation areas and transformation of parafluvial wetlands in Punarbhaba-Tangon river basin of IndoBangladesh. Geocarto International, 34(10), pp.1055-1074. 
Saha, T.K. and Pal, S., 2019. Exploring physical wetland vulnerability of Atreyee river basin in India and Bangladesh using logistic regression and fuzzy logic approaches. Ecological indicators, 98, pp.251-265.

Pal, S., Saha, A. and Das, T., 2019. Analysis of flow modifications and stress in the Tangon river basin of the Barind tract. International Journal of River Basin Management, 17(3), pp.301-321.

Pal, S. and Paul, S., 2020. Assessing wetland habitat vulnerability in moribund Ganges delta using bivariate models and machine learning algorithms. Ecological Indicators, 119, p.106866.

Pal, S. and Sarda, R., 2020. Damming effects on the degree of hydrological alteration and stability of wetland in lower Atreyee River basin. Ecological Indicators, 116, p.106542.

Pal, S. and Talukdar, S., 2020. Modelling seasonal flow regime and environmental flow in Punarbhaba river of India and Bangladesh. Journal of Cleaner Production, 252, p.119724.

Pal, S., Talukdar, S. and Ghosh, R., 2020. Damming effect on habitat quality of riparian corridor. Ecological Indicators, 114, p.106300.

Pal, S. and Sarda, R., 2021a. Measuring the degree of hydrological variability of riparian wetland using hydrological attributes integration (HAI) histogram comparison approach (HCA) and range of variability approach (RVA). Ecological Indicators, 120, p.106966.

Pal, S. and Sarda, R., 2021b. Modelling water richness in riparian flood plain wetland using bivariate statistics and machine learning algorithms and figuring out the role of damming. Geocarto International, pp.1-24.

Pal, S., Sarkar, R. and Saha, T.K., 2022. Exploring the forms of wetland modifications and investigating the causes in lower Atreyee river floodplain area. Ecological Informatics, 67, p.101494.

Quintela, F.M., Lima, G.P., Silveira, M.L., Costa, P.G., Bianchini, A., Loebmann, D. and Martins, S.E., 2019. High arsenic and low lead concentrations in fish and reptiles from Taim wetlands, a Ramsar site in southern Brazil. Science of the Total Environment, 660, pp.10041014. 
935

936

937

938

939

940

941

942

943

944

945

946

947

948

949

950

951

952

953

954

955

956

957

958

959

960

Rahmati, O., Falah, F., Dayal, K.S., Deo, R.C., Mohammadi, F., Biggs, T., Moghaddam, D.D., Naghibi, S.A. and Bui, D.T., 2020. Machine learning approaches for spatial modeling of agricultural droughts in the south-east region of Queensland Australia. Science of the Total Environment, 699, p.134230.

Richter, B.D., Baumgartner, J.V., Braun, D.P. and Powell, J., 1998. A spatial assessment of hydrologic alteration within a river network. Regulated Rivers: Research \& Management: An International Journal Devoted to River Research and Management, 14(4), pp.329-340

Rolls, R.J., Leigh, C. and Sheldon, F., 2012. Mechanistic effects of low-flow hydrology on riverine ecosystems: ecological principles and consequences of alteration. Freshwater Science, 31(4), pp.1163-1186.

Saha, T.K. and Pal, S., 2019a. Emerging conflict between agriculture extension and physical existence of wetland in post-dam period in Atreyee River basin of IndoBangladesh. Environment, Development and Sustainability, 21(3), pp.1485-1505.

Saha, T.K. and Pal, S., 2019b. Exploring physical wetland vulnerability of Atreyee river basin in India and Bangladesh using logistic regression and fuzzy logic approaches. Ecological indicators, 98, pp.251-265.

Saha, T.K., Pal, S. and Sarkar, R., 2021. Prediction of wetland area and depth using linear regression model and artificial neural network based cellular automata. Ecological Informatics, 62, p.101272.

Sahour, H., Kemink, K.M. and O’Connell, J., 2022. Integrating SAR and Optical Remote Sensing for Conservation-Targeted Wetlands Mapping. Remote Sensing, 14(1), p.159.

Santos, C.A.G., Kisi, O., da Silva, R.M. and Zounemat-Kermani, M., 2018. Wavelet-based variability on streamflow at 40-year timescale in the Black Sea region of Turkey. Arabian Journal of Geosciences, 11(8), pp.1-11.

Sarkar, U.K., Mishal, P., Borah, S., Karnatak, G., Chandra, G., Kumari, S., Meena, D.K., Debnath, D., Yengkokpam, S., Das, P. and DebRoy, P., 2020. Status, potential, prospects, and 
961 issues of floodplain wetland fisheries in India: synthesis and review for sustainable 962 management. Reviews in Fisheries Science \& Aquaculture, 29(1), pp.1-32.

963 Sarda, R. and Das, P., 2018. Monitoring changing trends of water presence state in the major 964 manmade reservoirs of Mayurakshi river basin, eastern India. Spatial Information $965 \quad$ Research, 26(4), pp.437-447.

966 Shaikhina, T., Lowe, D., Daga, S., Briggs, D., Higgins, R. and Khovanova, N., 2019. Decision 967 tree and random forest models for outcome prediction in antibody incompatible kidney 968 transplantation. Biomedical Signal Processing and Control, 52, pp.456-462.

969 Shen, G., Yang, X., Jin, Y., Xu, B. and Zhou, Q., 2019. Remote sensing and evaluation of the 970 wetland ecological degradation process of the Zoige Plateau Wetland in China. Ecological 971 Indicators, 104, pp.48-58

972 Shiau, J.T. and Wu, F.C., 2008. A histogram matching approach for assessment of flow regime 973 alteration: application to environmental flow optimization. River Research and 974 Applications, 24(7), pp.914-928.

975 Singha, P., Das, P., Talukdar, S. and Pal, S., 2020. Modeling livelihood vulnerability in erosion 976 and flooding induced river island in Ganges riparian corridor, India. Ecological Indicators, 119, 977 p.106825.

978 Smith, L.C., Turcotte, D.L. and Isacks, B.L., 1998. Stream flow characterization and feature 979 detection using a discrete wavelet transform. Hydrological processes, 12(2), pp.233-249.

980 Smith, A., Tetzlaff, D., Gelbrecht, J., Kleine, L. and Soulsby, C., 2020. Riparian wetland 981 rehabilitation and beaver re-colonization impacts on hydrological processes and water quality in 982 a lowland agricultural catchment. Science of the Total Environment, 699, p.134302.

983 Talukdar, S. and Pal, S., 2019. Effects of damming on the hydrological regime of Punarbhaba 984 river basin wetlands. Ecological Engineering, 135, pp.61-74.

985 Talukdar, S. and Pal, S., 2020. Modeling flood plain wetland transformation in consequences of 986 flow alteration in Punarbhaba river in India and Bangladesh. Journal of Cleaner 987 Production, 261, p.120767. 
988 Teng, J., Xia, S., Liu, Y., Yu, X., Duan, H., Xiao, H. and Zhao, C., 2021. Assessing habitat 989 suitability for wintering geese by using Normalized Difference Water Index (NDWI) in a large 990 floodplain wetland, China. Ecological Indicators, 122, p.107260.

991 Tian, X., Zhao, G., Mu, X., Zhang, P., Tian, P., Gao, P. and Sun, W., 2019. Hydrologic alteration 992 and possible underlying causes in the Wuding River, China. Science of the Total 993 Environment, 693, p.133556.

994 Tian, Y., Xu, C., Hong, H., Zhou, Q. and Wang, D., 2019. Mapping earthquake-triggered 995 landslide susceptibility by use of artificial neural network (ANN) models: an example of the 9962013 Minxian (China) Mw 5.9 event. Geomatics, Natural Hazards and Risk, 10(1), pp.1-25.

997 Tonkin, J.D., Merritt, D.M., Olden, J.D., Reynolds, L.V. and Lytle, D.A., 2018. Flow regime 998 alteration degrades ecological networks in riparian ecosystems. Nature ecology \& 999 evolution, 2(1), pp.86-93.

1000 Tootchi, A., Jost, A. and Ducharne, A., 2019. Multi-source global wetland maps combining 1001 surface water imagery and groundwater constraints. Earth System Science Data, 11(1), pp.1891002220.

1003 Urzică, A., Mihu-Pintilie, A., Stoleriu, C.C., Cîmpianu, C.I., Huţanu, E., Pricop, C.I. and 1004 Grozavu, A., 2021. Using 2D HEC-RAS Modeling and Embankment Dam Break Scenario for 1005 Assessing the Flood Control Capacity of a Multi-Reservoir System (NE Romania). Water, 13(1), 1006 p.57.

1007 van Oorschot, M., Kleinhans, M., Buijse, T., Geerling, G. and Middelkoop, H., 2018. Combined 1008 effects of climate change and dam construction on riverine ecosystems. Ecological 1009 engineering, 120, pp.329-344.

1010 Vidon, P.G., Welsh, M.K. and Hassanzadeh, Y.T., 2019. Twenty years of riparian zone research 1011 (1997-2017): Where to next?. Journal of environmental quality, 48(2), pp.248-260.

1012 Wang, Y., Zhang, N., Wang, D., Wu, J. and Zhang, X., 2018. Investigating the impacts of 1013 cascade hydropower development on the natural flow regime in the Yangtze River, 1014 China. Science of the total environment, 624, pp.1187-1194. 
1015 Wang, D., Zhang, S., Wang, G., Han, Q., Huang, G., Wang, H., Liu, Y. and Zhang, Y., 2019. 1016 Quantitative assessment of the influences of Three Gorges Dam on the water level of Poyang 1017 Lake, China. Water, 11(7), p.1519.

1018 Wang, Y., Zhang, N., Wang, D. and Wu, J., 2020. Impacts of cascade reservoirs on Yangtze 1019 River water temperature: Assessment and ecological implications. Journal of Hydrology, 590, 1020 p.125240.

1021 Ward JV, Stanford JA (1989) The four-dimensional nature of lotic ecosystems. J N Am Benthol 1022 Soc 8:2-8

1023 Wondie, A., 2018. Ecological conditions and ecosystem services of wetlands in the Lake Tana 1024 Area, Ethiopia. Ecohydrology \& Hydrobiology, 18(2), pp.231-244.

1025 Xiong, J., Li, J., Cheng, W., Wang, N. and Guo, L., 2019. A GIS-based support vector machine 1026 model for flash flood vulnerability assessment and mapping in China. ISPRS International 1027 Journal of Geo-Information, 8(7), p.297.

1028 Xue, L., Zhang, H., Yang, C., Zhang, L. and Sun, C., 2017. Quantitative assessment of 1029 hydrological alteration caused by irrigation projects in the Tarim River basin, China. Scientific 1030 Reports, 7(1), pp.1-13.

1031 Yabusaki, S.B., Myers-Pigg, A.N., Ward, N.D., Waichler, S.R., Sengupta, A., Hou, Z., Chen, X., 1032 Fang, Y., Duan, Z., Serkowski, J.A. and Indivero, J., 2020. Floodplain inundation and 1033 salinization from a recently restored first-order tidal stream. Water Resources Research, 56(7), 1034 p.e2019WR026850.

1035 Yan, Y., Yang, Z., Liu, Q. and Sun, T., 2010. Assessing effects of dam operation on flow 1036 regimes in the lower Yellow River. Procedia Environmental Sciences, 2, pp.507-516.

1037 Yang, T., Zhang, Q., Chen, Y.D., Tao, X., Xu, C.Y. and Chen, X., 2008. A spatial assessment of 1038 hydrologic alteration caused by dam construction in the middle and lower Yellow River, 1039 China. Hydrological Processes: An International Journal, 22(18), pp.3829-3843.

1040 Zheng, Y., Zhang, G., Wu, Y., Xu, Y.J. and Dai, C., 2019. Dam effects on downstream riparian 1041 wetlands: the Nenjiang River, Northeast China. Water, 11(10), p.2038. 
1042 Declarations

1043 Ethical Approval

1044 Not applicable

1045 Consent to Participate

1046 Not applicable

1047 Consent to Publish

1048 Not applicable

1049 Authors Contributions

1050 All authors contributed to the study's conception and design. Conceptualization; Methodology 1051 designing; Writing - review \& editing were performed by Dr. Swades Pal. Data curation; 1052 Investigation; Software; Validation; and Writing - original draft were performed by Rajesh Sarda 1053 and Dr. Tamal Kanti Saha. All the authors read and approved the final manuscript.

1054 Funding

1055 The corresponding author of the article (Rajesh Sarda) would receive a Junior Research 1056 fellowship to conduct the research work.

1057 Competing Interests

1058 The authors declare that they have no competing interests

1059 Availability of data and materials

1060 The datasets used and/or analyzed during the research work are available from the corresponding 1061 author on reasonable request. 